\title{
BONN, GERMANY
}

A Territorial Approach to the Sustainable Development Goals in Bonn, Germany

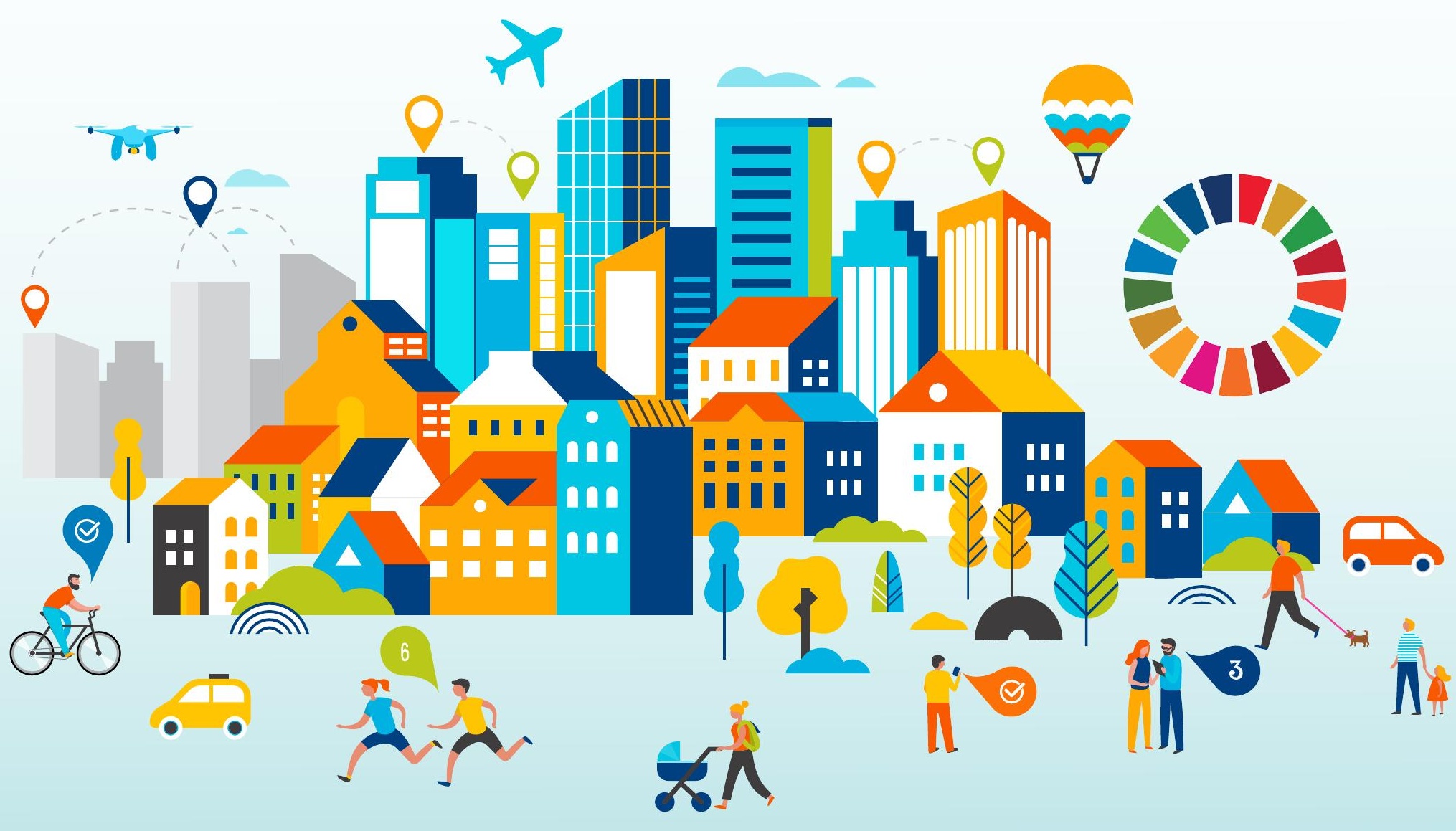




\section{A Territorial Approach to the Sustainable Development Goals in Bonn, Germany}




\section{ABOUT THE OECD}

The OECD is a multi-disciplinary inter-governmental organisation of 37 member countries which engages in its work an increasing number of non-members from all regions of the world. The Organisation's core mission today is to help governments work together towards a stronger, cleaner, fairer global economy. Through its network of 250 specialised committees and working groups, the OECD provides a setting where governments compare policy experiences, seek answers to common problems, identify good practice, and co-ordinate domestic and international policies. More information available: www.oecd.org.

\section{ABOUT OECD REGIONAL DEVELOPMENT PAPERS}

Papers from the Centre for Entrepreneurship, SMEs, Regions and Cities of the OECD cover a full range of topics including regional statistics and analysis, urban governance and economics, rural governance and economics, and multi-level governance. Depending on the programme of work, the papers can cover specific topics such as regional innovation and networks, sustainable development, the determinants of regional growth or fiscal consolidation at the sub-national level. OECD Regional Development Papers are published on http://www.oecd.org/cfe/regional-policy.

This paper was authorised for publication by Lamia Kamal-Chaoui, Director, Centre for Entrepreneurship, SMEs, Regions and Cities, OECD.

This document, as well as any statistical data and map included herein, are without prejudice to the status of or sovereignty over any territory, to the delimitation of international frontiers and boundaries and to the name of any territory, city or area.

Photo credits: Cover @ ma_rish/iStock/Getty Images Plus.

\section{C) OECD 2020}

You can copy, download or print OECD content for your own use, and you can include excerpts from OECD publications, databases and multimedia products in your own documents, presentations, blogs, websites and teaching materials, provided that suitable acknowledgement of OECD as source and copyright owner is given. All requests for public or commercial use and translation rights should be submitted to rights@oecd.org. 


\section{Preface}

The SDGs have become even more important than ever. We are therefore delighted to introduce the results of our 2-year policy dialogue with $100+$ stakeholders to promote a territorial approach to the Sustainable Development Goals (SDGs) in Bonn, Germany. While the City of Bonn is looking into longterm measures to face pandemics like Covid-19, the SDGs provide a comprehensive framework to build a more sustainable and resilient society.

To support its commitment towards a low-carbon economy and international development cooperation, Bonn has embraced the 2030 Agenda and the SDGs as a framework to design, plan and implement the strategic goals of the city's 2030 Sustainability Strategy. The Strategy seeks to address the main challenges faced by the city in terms of providing affordable housing, expanding and maintaining green spaces, shifting to clean forms of transport and energy, and providing employment opportunities for all, especially for low-skilled workers. This commitment has accelerated with the 2019 City Council Statement declaring a Climate Emergency, leading to 150 measures to achieve climate neutrality by 2035, including an additional budget for climate-friendly actions foreseen in the 2021/22 budget.

Drawing on the OECD's concept of Functional Urban Areas (FUA), which allows to analyse urban development challenges beyond a city's administrative boundaries, the OECD report $A$ Territorial Approach to the Sustainable Development Goals in Bonn, Germany provides guidance on how the SDGs can help to institutionalise Bonn's Sustainability Strategy and allocate adequate resources to its implementation. They also provide an integrated framework to manage trade-offs between climate, sustainable mobility and affordable housing goals, while striving to reduce inequalities. Based on the OECD Checklist for Public Action to localise the SDGs, the report also calls for a shared responsibility across levels of government in the areas of planning, policies and strategies; multi-level governance; financing and budgeting; data and information, and stakeholder engagement. To that effect, it provides recommendations to strengthen the engagement of the business community in the Sustainability Strategy and involve the city leadership in the Voluntary National Review process of Germany, a recommendation which Bonn pursues further by presenting its first Voluntary Local Review in July 2020.

We are grateful for the inclusive consultation process underlying this report, whereby we listened and learned from each other, built on our respective knowledge and experience, and strived to collect and be inspired from best practices to move forward Bonn's Sustainability Strategy over the years to come. In addition to the active participation of stakeholders from the City of Bonn and other levels of government, including the Federal Government and the Service Agency Communities in One World on behalf of Engagement Global that are supporting cities in localising the SDGs, the report benefited from the valuable insights from peers in the City of Kitakyushu (Japan), as well as numerous institutions from public, private, academic, and non-profit sectors to build consensus, discuss the policy recommendations, and scale-up success stories.

Moving forward, using the SDGs as a framework to implement the Sustainability Strategy will help the city to include the lessons learnt from the Covid-19 pandemic and to build a more resilient and inclusive society, while pursuing the climate commitments.

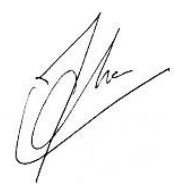

Lamia Kamal-Chaoui,

Director, OECD Centre for Entrepreneurship, SMEs, Regions and Cities

\section{thele Sridharan}

Ashok Sridharan, Mayor of the City of Bonn, Germany 


\section{Acknowledgements}

This report was prepared by the OECD Centre for Entrepreneurship, SMEs, Regions and Cities (CFE) led by Lamia Kamal-Chaoui, Director, as part of the Programme of Work and Budget of the Regional Development Policy Committee. It is the result of a two-year policy dialogue with 100+ stakeholders from public, private and non-profit sectors and from across all levels of government in Germany.

The report was drafted by a core team of OECD policy analysts comprised of Stina Heikkilä, Antonio Canamas Catala and Lorenz Gross of the CFE, led by Stefano Marta, Coordinator of the OECD Programme on a Territorial Approach to the SDGs, under the supervision of Aziza Akhmouch, Head of the Cities, Urban Policies and Sustainable Development Division in the CFE. The report benefited from the support of Marcos Díaz Ramírez, Statistician, who produced the local SDGs data for the FUA of Bonn, Germany.

The OECD Secretariat is grateful for the high-level political impetus and commitment from Ashok Sridharan, Mayor of the city of Bonn, and Stefan Wagner, Head of Department of International Affairs and Global Sustainability. Special thanks are herein conveyed to the excellent local team in the city of Bonn, directed by Verena Schwarte, Department of International Affairs and Global Sustainability, and composed of Achim Helbig, Christine Pflüger and Marion Wilde from the Department for Environment, Consumer Protection and Local Agenda; Birgit Rücker from the Department of International Affairs and Global Sustainability as well as numerous other colleagues from the city of Bonn, who assisted in the missions and the preparation of the report. Special thanks also to Sebastian Dürselen from the project Municipalities for Global Sustainability on behalf of Engagement Global for the support throughout the design and implementation of the policy dialogue and to the Service Agency of Communities in One World of Engagement Global for the financial support to the city of Bonn for the participation in the project, funded by the Ministry of Economic development and cooperation (BMZ). Furthermore, the policy dialogue benefited from insights from peer reviewers of the city of Kitakyushu (Japan), who contributed through their valuable expertise and experience, participated in missions and provided international best practices as well as guidance on the report, namely, Masanori Nakagawa, Director, Environmental Bureau, and Junko Ota, Policy Researcher, Institute for Global Environmental Strategies (IGES). Special thanks are conveyed to the many stakeholders engaged throughout the policy dialogue via interviews, seminars and workshops.

The report was submitted for approval by written procedure to the Regional Development Policy Committee by 23 June 2020 under the cote CFE/RDPC/URB(2020)10.

Special thanks are extended to François Iglesias and Pilar Philip in the CFE for preparing the report for publication, as well as to Eleonore Morena for editing and formatting the report. 


\section{Table of contents}

Preface 3

$\begin{array}{ll}\text { Acknowledgements } & 4\end{array}$

$\begin{array}{lc}\text { Abbreviations and acronyms } & 8\end{array}$

Executive summary 10

1 A solid policy framework that builds on sustainability and climate commitments of Bonn, Germany 15

Key facts on the city of Bonn, Germany $\quad 16$

Bonn's historical journey towards a sustainability hub 17

The Sustainability Strategy of the city of Bonn: Using the SDGs to identify policy priorities 18 Institutionalising the Sustainability Strategy: Main functions, budgeting process and reporting 22

A need to link the 2019 Sustainability Strategy to the municipal budget 23

Tracking progress of Bonn's Sustainability Strategy 23

Bonn's commitment to climate action and global responsibility 25

$\begin{array}{lr}\text { References } & 26\end{array}$

$\begin{array}{lr}\text { Notes } & 27\end{array}$

2 Sustainable development challenges and opportunities in Bonn, Germany 29

Measuring the distance to the SDGs in Bonn, Germany 30

Dimension People: Good health is a key strength while old-age poverty is an emerging challenge

Dimension Planet: Commitment to biodiversity and low emissions, but car usage and waste are pressing issues transport are challenges Dimensions Peace and Partnership: Citizen participation and the commitment to international co-operation are strong assets

The SDGs: A means to link environmental, economic and social performance in Bonn, Germany 47

$\begin{array}{ll}\text { References } & 50\end{array}$

$\begin{array}{lr}\text { Notes } & 51\end{array}$

3 The SDGs to strengthen the multi-level governance for sustainability in Bonn and Germany

A solid multi-level governance framework that builds on sustainability and climate commitment 54

Strategic alignment across federal, Länder and local governments $\quad 54$

Co-ordination mechanisms in place $\quad 54$ 
Collaboration between German cities and municipalities on the 2030 Agenda 56

The SDGs as a tool to engage the private sector and civil society in Bonn's Sustainability Strategy

Bonn as a growing hub for sustainability-oriented businesses

Private sector engagement: A future focus in Bonn's Sustainability Strategy

Bonn's actions to raise civil society awareness on the SDGs

\section{Tables}

Table 1.1. Key priority SDGs for the city of Bonn from the OECD Survey 22

Table 2.1. OECD indicators used to assess the dimension People in the FUA of Bonn 33

Table 2.2. Selected Bonn-specific administrative indicators used to assess the dimension People 35

Table 2.3. OECD indicators used to assess the dimension Planet in the FUA of Bonn 37

Table 2.4. Selected Bonn-specific administrative indicators used to assess the dimension Planet 39

Table 2.5. OECD indicators used to assess the dimension Prosperity in the FUA of Bonn 40

Table 2.6. Selected Bonn-specific administrative indicators used to assess the dimension Prosperity 43

Table 2.7. OECD indicators used to assess the dimensions Peace and Partnership in the FUA of Bonn $\quad 44$

Table 2.8. Selected Bonn-specific administrative indicators used to assess the dimensions Peace and

Partnership

\section{Figures}

Figure 1.1. OECD's analytical framework for the programme A Territorial Approach to the SDGs 20

Figure 1.2. The six priority areas in the city of Bonn's Sustainability Strategy 21

Figure 2.1. The 17 Sustainable Development Goals $\quad 30$

Figure 2.2. Functional Urban Area of Bonn $\quad 32$

Figure 2.3. FUA of Bonn and the SDGs - Distance to the end values 33

Figure 2.4. Transport-related mortality rates - Deaths per 100000 people (2017): Comparison across FUAs 34

Figure 2.5. Demographic structure in the city of Bonn, 2002-18 36

Figure 2.6. Number of places available in nurseries and day care facilities per 100 children aged 0 to under 3 years in the city of Bonn

Figure 2.7. Terrestrial protected areas as a percentage of total area (2017): Comparison across FUAs 38

Figure 2.8. Length of cycle paths per metre of traffic routes in the city of Bonn 40

Figure 2.9. Percentage of total electricity production that comes from fossil fuels - Natural gas and oil, excluding coal (2019): Comparison across FUAs

Figure 2.10. Number of newly registered businesses per 100 de-registered businesses in the city of Bonn Figure 2.11. Percentage of houses and buildings connected to optical fibre networks (2017): Comparison across FUAs

Figure 2.12. Number of criminal offences recorded per 1000 inhabitants (2018) in the city of Bonn

Figure 2.13. Demographic dynamics in the city of Bonn and its functional urban area, 2011-18

\section{Boxes}

Box 1.1. Why a territorial approach to the SDGs? 
Box 1.2. Bertelsmann Foundation's SDG Indicators for German Municipalities 24

Box 2.1. OECD methodology for measuring cities' and regions' distance to the SDGs 30

Box 2.2. Definition of functional urban areas (FUAs) 32

$\begin{array}{lr}\text { Box 3.1. Bonn SDG Days } & 57\end{array}$

Box 3.2. Social City Tannenbusch $\quad 58$

Box 4.1. OECD Checklist for Public Action to localise the SDGs in cities and regions 62

\section{Follow OECD Publications on:}

Y http://twitter.com/OECD_Pubs

f $h$ htp://www.facebook.com/OECDPublications

in. http://www.linkedin.com/groups/OECD-Publications-4645871

Dhttp://www.youtube.com/oecdilibrary

OECD $h$ Altp://www.oecd.org/oecddirect/ 


\section{Abbreviations and acronyms}

$\mathrm{BMZ}$

CAESAR

CEMR

CFE

CSR

DIAGS

ECOPROFIT

EMAS

ESD

EU

FUA

GDP

ICLEI

IGES

IKVS

IMA Stadt

LAG 21

LAU

NDC

NRW

OECD

RENN

SDGs

SKEW

SME

SSC

SWB
Federal Ministry for Economic Cooperation and Development

Center of Advanced European Studies and Research

Council of European Municipalities and Regions

OECD Centre for Entrepreneurship, SMEs, Regions and Cities

Corporate Social Responsibility

Department of International Affairs and Global Sustainability

Ecological Project for Integrated Environmental Technology

Eco-Management and Audit Scheme

Education for Sustainable Development

European Union

Functional Urban Area

Gross Domestic Product

International Council for Local Environmental Initiatives - Local Governments for Sustainability

Institute for Global Environmental Strategies

Intercommunal Comparison Systems

Inter-ministerial working group for sustainable urban development

State Working Group Agenda 21

Local administrative unit

Nationally determined contribution

North Rhine-Westphalia

Organisation for Economic Co-operation and Development

Regional network offices - sustainability strategies

Sustainable Development Goals

Service Agency Communities in One World

Small and medium-sized enterprise

State Secretaries' Committee

Stadtwerke Bonn 
UN

UN-SPIDER

UNCCD

UNEP

UNESCO-UNEVOC

UNFCCC

UNDRR

UNV

VLR

VNR

WCCB

WHO

ZEF

ZEI
United Nations

United Nations Platform for Space-based Information for Disaster Management and Emergency Response

United Nations Convention to Combat Desertification in Those Countries Experiencing Serious Drought and/or Desertification, Particularly in Africa (UNCCD)

United Nations Environment Programme

International Centre for Technical and Vocational Education and Training of the United Nations Educational, Scientific and Cultural Organization

United Nations Framework Convention on Climate Change

United Nations Office for Disaster Risk Reduction

United Nations Volunteers

Voluntary Local Review

Voluntary National Review

World Conference Center Bonn

World Health Organization

Center for Development Research - University of Bonn

Center for European Integration Studies 


\section{Executive summary}

In the Covid-19 recovery context, the United Nations (UN) Sustainable Development Goals (SDGs) provide a long-term vision and an integrated framework to rethink the "new normal" though the lens of sustainability and to engage local stakeholders, including the private sector, civil society and citizens, in co-creating a more resilient city in Bonn, Germany.

Bonn's strong commitment to transition towards a low-carbon economy and achieving carbon neutrality by 2035 will require managing interlinkages and trade-offs across economic, social and environmental policy outcomes. After the move of Germany's federal government seat to the city of Berlin in 1991, Bonn established itself as an innovation business hub for information technology (IT), telecommunications and knowledge-based industries. It also placed itself as Germany's UN City, with a particular focus on sustainable development. Building on this, Bonn's Sustainability Strategy and climate agenda set ambitious goals for the city to remain an attractive place to live in the $21^{\text {st }}$ century. In particular, the city has been using the SDGs as a systemic framework to align priorities across climate, energy, housing, transport and inclusion policies.

\section{Key findings}

\section{A strong policy framework that builds on sustainability and climate commitments}

- Approved in 2019, Bonn's Sustainability Strategy identified SDG 11 as an ambitious framework to drive the city's well-being. The strategy sets long-term ambition to be reached by 2030 as well as short- and medium-term operational goals for the period 2022-24. Its key objective is to leverage synergies with priorities related to clean and affordable energy, responsible production and consumption and climate change.

- To accelerate progress towards the climate objectives of the Sustainability Strategy Bonn's city council declared a climate emergency in July 2019, followed by a catalogue of 150 climate actions and adaption suggestions by the administration. In November 2019 the city council adopted a resolution to make the city climate neutral by 2035 . The administration is planning to include an additional specific budget for this objective in the 2021/2022 budget to finance projects.

\section{Sustainable mobility, air pollution and affordable housing as three overarching priorities}

- The performance of Bonn's functional urban area (Bonn's FUA) towards the SDGs is very similar to the rest of OECD FUAs, on average ${ }^{1}$. However, important disparities emerge when looking at individual SDGs. Bonn's FUA goes beyond the administrative boundaries of Bonn and includes Bonn's surrounding area consisting of 19 additional municipalities (see Box 2.2).

\footnotetext{
${ }^{1}$ The FUA Bonn includes the city of Bonn as well as large parts of the Rhein-Sieg-Kreis and has a total population of around 925000 persons.
} 
- Bonn is strong in economic performance, research and development (R\&D), healthcare and green amenities:

- GDP per employee (EUR 94325 in 2018) in the city of Bonn is the second-highest among all cities and regions in the state of North Rhine-Westphalia, where Bonn is located.

- There are more than twice as many patent applications in the FUA of Bonn as in the average OECD FUA.

- The infant mortality rate (2.5) is lower than the average of OECD FUAs and more than $90 \%$ of the population has access to a hospital within a 20-minute drive.

- $99 \%$ of the population of the FUA of Bonn has access to at least 1 hectare of green area within 15 minutes of walking.

- Whereas, energy, transport and air pollution are policy areas with room for improvement:

- The residents of Bonn's FUA use a higher number of motor vehicles (49 per 100 people) than the average of OECD FUAs. In the city of Bonn itself, the motor vehicle per capita ratio is lower (40 per 100 people) than in the FUA and also lower than in Germany on average. Nevertheless, commuting by private car, as driver or additional passenger, is the most popular option in the city of Bonn (41\%).

- Bonn's FUA registered an average exposure to PM2.5 of $11.5 \mathrm{in} \mu \mathrm{g} / \mathrm{m}^{3}$ (micrograms per cubic metre) and around $87 \%$ of the population in the FUA of Bonn is exposed to more than $10 \mu \mathrm{g} / \mathrm{m}^{3}$ (OECD average is $60 \%$ ), which remains higher than the $10 \mu \mathrm{g} / \mathrm{m}^{3}$ recommended by the World Health Organization (WHO) and set as an end value by 2030 under SDG11.

- The average rent in Bonn has increased by 14\% between 2014 and 2018 making Bonn the fourth most expensive rental market in the state of North Rhine-Westphalia. Housing prices have increased by more than $30 \%$ in the same period.

- The population in the FUA of Bonn has increased by $4.7 \%$ between 2011 and 2019 and its built-up area is growing faster than the population size. With this growing population comes a higher demand for housing, energy and transport, which is adding pressure to the city's urban development.

- Old-age poverty is becoming one of the crucial social policy issues in Bonn. In the city of Bonn, the proportion of recipients of basic income support aged 65 and over as a percentage of the total population has been constantly growing in recent years. In 2006 , the share was $3.8 \%$, before surpassing the 5\% threshold in 2013 and reaching more than $6.3 \%$ in 2018, significantly exceeding the North Rhine-Westphalia state average of $4 \%$.

\section{The SDGs as a tool to foster a multi-level approach to sustainability}

- Sustainability strategies and policy priorities across federal, state and local governments are well-aligned. However, co-ordinating indicator systems to measure SDG progress remains a challenge. Through the federal programme Municipalities for Global Sustainability, Bonn has developed its Sustainability Strategy aligned with both national and state-level strategies. However, Bonn has only incorporated 14 out of the 47 SDG indicators developed by the Bertelsmann Foundation to monitor the implementation of the SDGs in Germany.

- Urban development challenges in Bonn exceed the administrative boundaries of the city and require a functional approach and co-operation with the city's hinterland and neighbouring municipalities. The built-up area per capita in the periphery is 2.3 times higher than in the core (administrative city of Bonn), thus leading to pronounced urban sprawl. The latter implies that strong co-ordination in transport policies could help mitigate an increase in private car utilisation and therefore contribute to other critical objectives such as climate mitigation or sustainable production. 
- The SDGs as a tool to engage business and civil society in the Sustainability Strategy. The Chamber for Industry and Commerce Bonn/Rhein-Sieg and the city of Bonn's Department for Economic Development actively connect local businesses working on sustainability. Supporting private sector collaboration beyond Corporate Social Responsibility (CSR), and thus strengthening the position of the city of Bonn as a cluster for sustainability-related SMEs should however play a more prominent role. The private sector has played a limited role in the development of Bonn's Sustainability Strategy, which should be addressed with adequate resources in the implementation phase.

- Bonn has made great efforts to raise the awareness of civil society and citizens at large on the 2030 Agenda, using the SDGs as an effective communication tool. Examples include the "SDG Days", organised by the city in cooperation with several local stakeholders and the Bonn SDG postcards explaining measures implemented by the city to achieve the SDGs. The Climate Ambassadors programme in schools is another successful example that has spread to other parts of the world through international co-operation projects between Bonn and peer cities in the global south.

\section{Policy recommendations}

Some key actions can help make the most of a territorial approach to the SDGs in Bonn:

- Raise the profile of the Sustainability Strategy to co-ordinate the implementation of the SDGs in a holistic manner in line with the climate agenda. To ensure this, Bonn should fully integrate the institutional mechanisms of the Sustainability Strategy into the organisational structure of the city administration. This will help to ensure continued efforts and framework conditions to implement the strategy through to 2030.

- Use the SDGs to strengthen the link between the climate agenda and the social and economic dimensions of sustainability. In particular:

- Consider the impact of climate measures on inequality, with special attention to vulnerable groups, in particular the elderly population and youth.

- Manage the trade-offs between providing additional affordable housing - due to rising rents and old-age poverty - and maintaining and developing green spaces to achieve climate objectives. Compensatory measures for vulnerable groups should also be considered.

- Consider the transport needs of a growing and elderly population when designing measures to reduce private transportation in favour of public transport to reduce air pollution.

- Stimulate the provision of clean and affordable energy as well as energy efficiency to generate cost savings and have positive effects for low-income populations.

- Support amongst others the creation of green businesses to pursue climate objectives and at the same time foster innovation, create sustainable jobs and enhance entrepreneurship.

- Pursue ongoing efforts to mainstream the SDGs in budgeting processes to ensure adequate resources are allocated for the implementation of Bonn's Sustainability Strategy and the 2030 Agenda, and to ensure policy continuity across political cycles. In the implementation phase of the strategy, financial resources should be allocated based on local policy priorities, challenges and expected impact, building on the ongoing efforts to introduce a sustainability budget in pilot areas within the city's budgeting process for 2020/2021. The SDGs can also be used as a means to foster integrated multi-sectoral programmes and priorities at the local level, in particular between initiatives and projects in the Sustainability Strategy and the Climate Emergency package.

- Develop an actionable evidence-based system to guide policy choices and decisions, building on Bonn's sustainability reporting and OECD data on the FUA of Bonn's distance 
to achieving the SDGs. Bonn should consider conducting more comprehensive assessments by using data from the Sustainability Report to identify key local development challenges and define policy priorities, combining data and indicators at different scales (administrative and functional urban area) and benchmarking with peer cities that face similar challenges.

- Step up the efforts by the city of Bonn to connect with the business community and leverage the potential of the private sector to contribute to the SDGs. First, the city department responsible for economic development could pursue the lead towards the implementation of the local Sustainability Strategy, including through catalysing needed technical, staff and financial resources. Second, a platform allowing sustainability-oriented businesses to connect could be set up to foster partnerships and innovations, as also indicated in the city's Sustainability Strategy. Lastly, sustainable public procurement could be further promoted to leverage funds from the private sector to achieve economic, social and environmental outcomes.

- Foster direct involvement of cities and municipalities in national processes for implementing, measuring and reporting on the SDGs. A first step in the right direction is Bonn's first Voluntary Local Review expected to be released in July 2020. The next Voluntary National Review of Germany in 2021 provides another opportunity to increase the visibility of the work carried out by municipalities such as Bonn to mainstream the SDGs in their planning, budgeting and policy. The Service Agency Communities in One World on behalf of Engagement Global and the German Associations of Cities could play a key role in advocating for enhanced involvement of local and regional governments. 



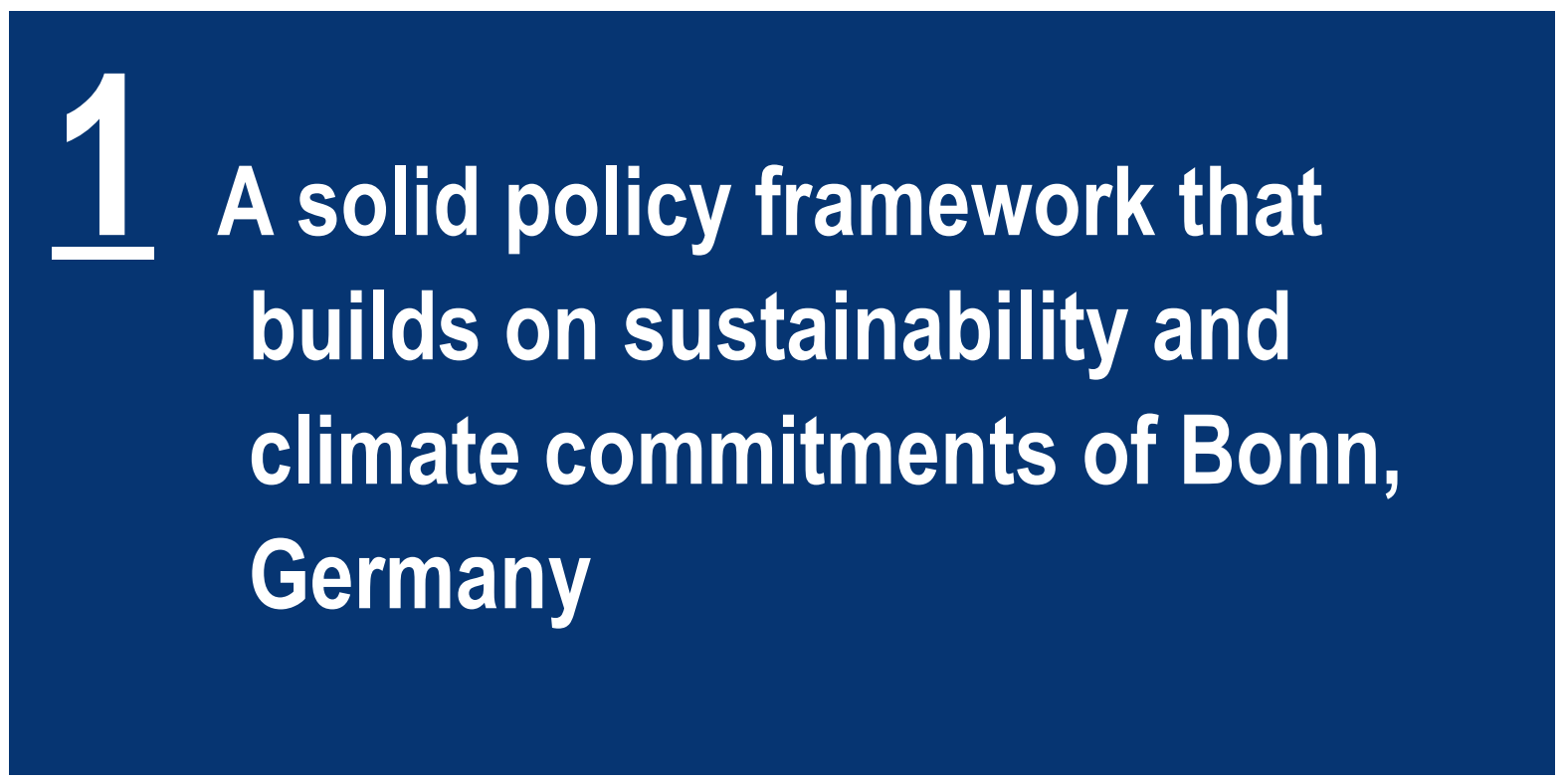

Over the past three decades, the Federal City of Bonn has emerged from its role as administrative capital to an international sustainability hub with a strong focus on the knowledge-based services sector, science and research. Building on a cluster of around 150 governmental and nongovernmental actors that work on sustainability, Bonn has seized the Sustainable Development Goals (SDGs) as a means to upscale its commitment towards sustainability. Key priorities identified in Bonn's Sustainability Strategy include: mobility; climate and energy; natural resources and environment; work and business; social participation and gender, and global responsibility. Institutionalising and funding the Sustainability Strategy are now the main priorities going forward for the local administration. 


\section{Key facts on the city of Bonn, Germany}

Bonn is one of the 20 largest and most dense cities in Germany. The Federal City of Bonn, capital of the Federal Republic of Germany from 1949 to 1990, is located on the banks of the Rhine in the southernmost part of the Rhine-Ruhr region. With a population of 332729 people (as of $1^{\text {st }}$ January 2020), Bonn is one of the 20 largest cities in Germany and overall the $9^{\text {th }}$-largest in the state of North Rhine-Westphalia. Covering an area of $141 \mathrm{~km}^{2}$, of which around one-third is built-up area, Bonn is also one of the 20 most densely populated cities in Germany. Its population is characterised by a high degree of cultural diversity. Around $30 \%$ of its 330000 inhabitants have an immigrant background, whereof more than 57000 are foreigners, mostly from Syria (8.6\%), Turkey (8.3\%) and Poland $(7.4 \%)$.

The city of Bonn has developed as one of Germany's main business locations for information technology (IT), telecommunications and knowledge-based industries. The city has a high concentration of academics and highly skilled workers and a growing business community and private sector employment. Bonn ranked second among German cities in terms of stock exchange value of the companies based in the city. In 2018, the gross domestic product (GDP) per employee in the city of Bonn reached EUR 94325 . This corresponds to the second largest GDP per employee among all cities and regions in the state of North Rhine-Westphalia. Bonn's average unemployment rate in 2018 was $6.4 \%$ following a downward trend from $7.3 \%$ in 2015. Among the 20 largest German cities, Bonn thus had the $8^{\text {th }}$-lowest unemployment rate. The unemployment rate in 2018 was lower than the average in the state of North Rhine-Westphalia, but above the average unemployment rate in Germany, which was $5.2 \%$ (City of Bonn, 2020[1]).

Small- and medium-sized enterprises (SMEs) account for more than $99 \%$ of businesses in Bonn and $60 \%$ of overall employment. In 2017, the city of Bonn counted 173531 employees subject to compulsory social insurance, around 40000 more than compared to the year 1991, when the federal government decided to move its main seat and core functions from Bonn to Berlin as part of the Unification Treaty of Germany in 1990 (Berlin-Bonn Act). Moreover, Bonn is home to 15640 companies (as of 31 December 2016). Enterprises with fewer than 250 employees accounted for $99.4 \%$ of all businesses in Bonn in 2016. Numbering 15550 entities, they provided 89658 jobs (58.6\% of the total) subject to social security contributions. On the other hand, the remaining 90 enterprises, that employ 250 or more people, play an almost equally important role for the economic structure and employment in Bonn. In 2016, they provided 63231 jobs (41.4\%) subject to social security contributions, which is a significantly higher percentage than in the state of North Rhine-Westphalia as a whole (33.0\%) but lower than in the state's major economic hubs Cologne (43.7\%) and Düsseldorf (43.8\%) (City of Bonn, 2020[2] ). The three largest private employers in Bonn are the formerly state-owned companies Deutsche Post DHL Group, Deutsche Telekom and Postbank that emerged from the former German Postal Service after the German reunification in 1990. Being all headquartered in Bonn, they together accounted for the employment of around 27600 people in Bonn in 2017. Deutsche Post DHL Group and Deutsche Telekom alone managed strategies for a global workforce of over 730000 from their head offices in Bonn (City of Bonn, 2020[2]).

The service sector is the backbone of economic activity in Bonn. In mid-2017, 91.9\% of overall employment in Bonn was in the service sector. In comparison, the corresponding state average of North Rhine-Westphalia was only $72.6 \%$. Together with Frankfurt am Main and Potsdam, Bonn ranks among the German cities with the most highly geared service economies. As a tertiary sector city, Bonn takes advantage of a sharp knowledge profile through the strong presence of knowledge-intensive services, which accounted for $37.3 \%$ of all employment in the city in mid-2017 compared to a state average of $22.1 \%$. Overall, around $30 \%$ of the employees in Bonn have obtained an academic degree, which is the $7^{\text {th }}$-highest ratio of cities in Germany (City of Bonn, 2020[1]). Healthcare, corporate management and IT Bonn's 3 strongest sectors - together account for close to a quarter (around 23.0\%) of the city's overall employment (City of Bonn, 2020 ${ }_{[3]}$ ). Public administration is another important economic pillar in Bonn accounting for more than $11 \%$ of overall employment (City of Bonn, $\left.2020_{[1]}\right)$. Manufacturing plays a smaller 
role for the city, representing $8.0 \%$ of employment in Bonn in 2017, notably in energy management and the automotive supply industry.

Science and research have an established tradition in the city of Bonn. The Bonn region is also a major location for research and innovation with a well-known higher education landscape, numerous international research institutions and major corporate research departments. Bonn is home to 6 universities and most notably known for the University of Bonn (Rheinische Friedrich Wilhelms-Universität Bonn), founded in 1818 and which has nowadays more than 34000 students from over 140 countries making it one of the largest universities in Germany. It has further been conferred the title of "University of Excellence" under the German Universities Excellence Initiative and is an important employer in the city of Bonn with a staff of around 6500 (The University of Bonn, 2019 ${ }_{[4]}$ ).

\section{Bonn's historical journey towards a sustainability hub}

A historic event that had a major impact on the city of Bonn was the decision by the federal government in 1991 to move its main seat and core functions from Bonn to Berlin, as part of the Unification Treaty of Germany in 1990. To regulate the transfer, the Berlin-Bonn Act signed in 1994 ensured a "permanent and fair division" of labour between the two cities. Nevertheless, the decision meant that over 30000 jobs in Bonn were at risk and that the city would need to undergo structural transformation. To facilitate this, a financial compensation agreement of EUR 1.43 billion was granted by the Federal Republic to support the transition in the city and its surrounding region between 1994 and 2004 (Information Service - Federal City of Bonn, $\left.2017_{[5]}\right)$.

The master plan for the redevelopment of Bonn presented shortly after the 1991 decision was structured around five key pillars that envisaged a new profile for the city of Bonn, namely: i) a federal city; ii) a centre for European and international co-operation (Germany's United Nations [UN] City); iii) a city of science and research; iv) a city with a forward-looking economic structure; and v) a cultural centre (as the birthplace of Beethoven) (City of Bonn, 2017[6]).

The main share of the financial compensation agreement of 1994 was invested in promoting Bonn as a city-region of science and research. This included establishing the Center of Advanced European Studies and Research (CAESAR), the Center for European Integration Studies (ZEI) and the Center for Development Research (ZEF), among others. Significant investment was also made in the Inter-City Express train connecting the Bonn-Cologne and Frankfurt airports (Information Service - Federal City of Bonn, 2017[5]). The city also invested in attracting businesses to locate in Bonn, as was the case of Deutsche Post (DHL) and Deutsche Telekom together with numerous subsidiaries (Kushner, 2001 ${ }_{[7]}$ ).

Today, Bonn is officially a "federal city", as it remains an important political centre in Germany as guaranteed by the Berlin-Bonn Act. Six federal ministries thus keep their primary offices in Bonn. These are the Ministries of Education and Research; Environment, Nature Conservation and Nuclear Safety; Health; Food, Agriculture and Consumer Protection; Economic Cooperation and Development; and Defence. The remaining ministries have their main seats in Berlin and second seats in Bonn. The city also hosts 20 state agencies that moved to Bonn as part of the 1994 compensation agreement. The city still engages in active negotiations with the federal government to ensure that public functions keep being located in Bonn.

Another prominent feature of Bonn's new profile is its role as Germany's UN City, with a particular focus on sustainable development under the slogan: "UN in Bonn: Shaping a sustainable future". While UN organisations have been located in the city since 1951, the UN Campus opened in 2006, nowadays hosting $23 \mathrm{UN}$ organisations with around 1000 staff $^{1}$. The UN organisations form part of a wider cluster of around 150 governmental and non-governmental organisations, scientific research institutions and other global players that work on sustainability. Key areas covered include climate change (e.g. United Nations 
Framework Convention on Climate Change, UNFCCC), volunteerism (United Nations Volunteers, UNV), desertification (United Nations Convention to Combat Desertification, UNCCD), disaster risk reduction (e.g. United Nations Platform for Space-based Information for Disaster Management and Emergency Response UN-SPIDER), education (e.g. International Centre for Technical and Vocational Education and Training of the United Nations Educational, Scientific and Cultural Organization, UNESCO-UNEVOC; United Nations University; UN System Staff College), and species conservation (e.g. United Nations Environment Programme [UNEP] Secretariat of the Convention of Migratory Species of Wild Animals). The UN SDG Action Campaign's Global Campaign Centre is also located in Bonn. The centre aims to provide country-level advocacy support to member states and partners across the globe (UN Bonn Information, 2018$[8]) . .^{2}$ In addition, Bonn is a renowned international conference location that has hosted key events like global climate summits, the International Conference on Freshwater, the United Nations Talks on Afghanistan and the Conference of the Parties of the UN Convention on Biological Diversity. Finally, the current mayor of Bonn is president of the international network organisation ICLEI - Local Governments for Sustainability.

\section{The Sustainability Strategy of the city of Bonn: Using the SDGs to identify policy priorities}

The Sustainability Strategy of the city of Bonn, adopted by the municipal council in February 2019, provides the city's overarching framework for localising the 2030 Agenda. It includes six priority areas that correspond to the city administration's municipal fields of action, namely: i) mobility; ii) climate and energy; iii) natural resources and the environment; iv) work and business; v) social participation and gender; and vi) global responsibility. For each of the priority areas, strategic goals are set for 2030 - linked to the SDGs - and thematic guidelines are provided (Figure 1.2). Under the strategic goals, operational targets translate the strategic priorities into a short- to medium-term roadmap (2020-22) with concrete measures such as expanding bicycle traffic, strengthening the use of renewable energies and raising awareness of global responsibility among citizens.

\section{Box 1.1. Why a territorial approach to the SDGs?}

Although the SDGs provide a global framework, the opportunities and challenges for sustainable development vary significantly across and within countries, regions and cities. The 2030 Agenda was not designed specifically for cities and regions, which nevertheless play a crucial role in achieving the SDGs. Indeed, cities and regions are an integral part of the solution as the varying nature of sustainable development challenges calls for place-based solutions tailored to territorial specificities, needs and capacities. The OECD estimates that at least 105 of the 169 targets underlying the 17 SDGs will not be reached without proper engagement and co-ordination with local and regional governments as cities and regions have core responsibilities that are central to sustainable development and well-being (e.g. water services, housing or transport). They are also responsible for a significant share of public investment $(60 \%$ in OECD countries), which is critical to channel the required funding to meet the SDGs.

Place-based policies relate to a set of co-ordinated actions specifically designed for a particular city or region and stress the need to shift from a sectoral to a multi-sectoral approach, from one-size-fits-all to context-specific measures and from a top-down to a bottom-up approach to policymaking. Based on the idea of policy co-ordination across sectors and multi-level governance, whereby all levels of government and non-state actors should play a role in the policy process, they consider and analyse functional territories, build on the endogenous development potential of each territory and use a wide range of actions (OECD, 2019 $[9]$ ). 
The SDGs can help to advance conceptually the shift towards a new regional development policy paradigm and provide a framework to implement it because:

- The 2030 Agenda provides a long-term vision for strategies and policies with a common milestone in 2030, while acknowledging that targeted action is needed in different places since their exposure to challenges and risk varies widely, as does their capacity to cope with them.

- The interconnected SDGs framework allows the promotion of policy complementarities and the management of trade-offs across goals. Indeed, the SDGs enable policymakers to address the social, economic and environmental dimensions of sustainable development concomitantly, building on synergies and taking interlinkages into account.

- The SDGs allow to better implement the concept of functional territories, a common framework that neighbouring municipalities can use to strengthen collaborations and to co-ordinate actions.

- The SDGs can be used to promote multi-level governance and partnerships, including the engagement of various stakeholders in the policymaking process.

\section{OECD's analytical framework for the programme A Territorial Approach to the SDGs}

The OECD has identified four critical megatrends influencing the achievement of the SDGs in cities and regions: i) demographic changes, in particular urbanisation, ageing and migration; ii) climate change and the need to transition to a low-carbon economy; iii) technological changes, such as digitalisation and the emergence of artificial intelligence; and iv) globalisation and the related geography of discontent. The SDGs provide a framework for cities and regions to respond systemically to such global megatrends. The proposed OECD framework foresees three key areas, policies and strategies, actors and tools, for cities and regions to implement a territorial approach to the SDGs.

\section{Policies and strategies}

Cities and regions can use the SDGs as a means to shift from a sectoral to a multi-sectoral approach, both in the design and in the implementation of their policies. The SDGs can help to bring various departments of a local administration together to strengthen the collaboration in policy implementation. Regional policy aims to effectively address the diversity of economic, social, demographic, institutional and geographic conditions across cities and regions. It also ensures that sectoral policies are co-ordinated with each other and meet the specific needs of different regions and provide the tools that traditional structural policies often lack in order to address region-specific factors that cause economic and social stagnation (OECD, 2019[9]).

\section{Tools}

The effective implementation of a territorial approach to the SDGs implies the combined use of a variety of tools. These span from a solid multi-level governance system to global and context-specific data for evidence-based policies. They also consist of combining functional and administrative approaches to address territorial challenges and opportunities beyond borders, as well as investment and incentives, in particular for the private sector to contribute. Multi-level governance represents a key tool to promote vertical co-ordination (across levels of government) and horizontal co-ordination (across ministries and departments) - both within the local, regional and national governments and between the government and other key stakeholders. National governments can also use the SDGs as a framework to promote policy coherence across levels of government, align priorities and rethink sustainable development through a bottom-up approach.

\section{Actors}

Participatory policymaking and a bottom-up process are one of the core elements of a territorial approach to the SDGs. Shifting from a top-down and hierarchical to a bottom-up and participatory 
approach to policymaking and implementation is key for the achievement of the SDGs. The 2030 Agenda requires a more transparent and inclusive model that involves public as well as non-state actors to co-design and jointly implement local development strategies and policies. The SDGs provide cities and regions with a tool to effectively engage in multi-stakeholder dialogues with actors from the private sector, civil society, as well as schools and academia.

\section{Figure 1.1. OECD's analytical framework for the programme A Territorial Approach to the SDGs}

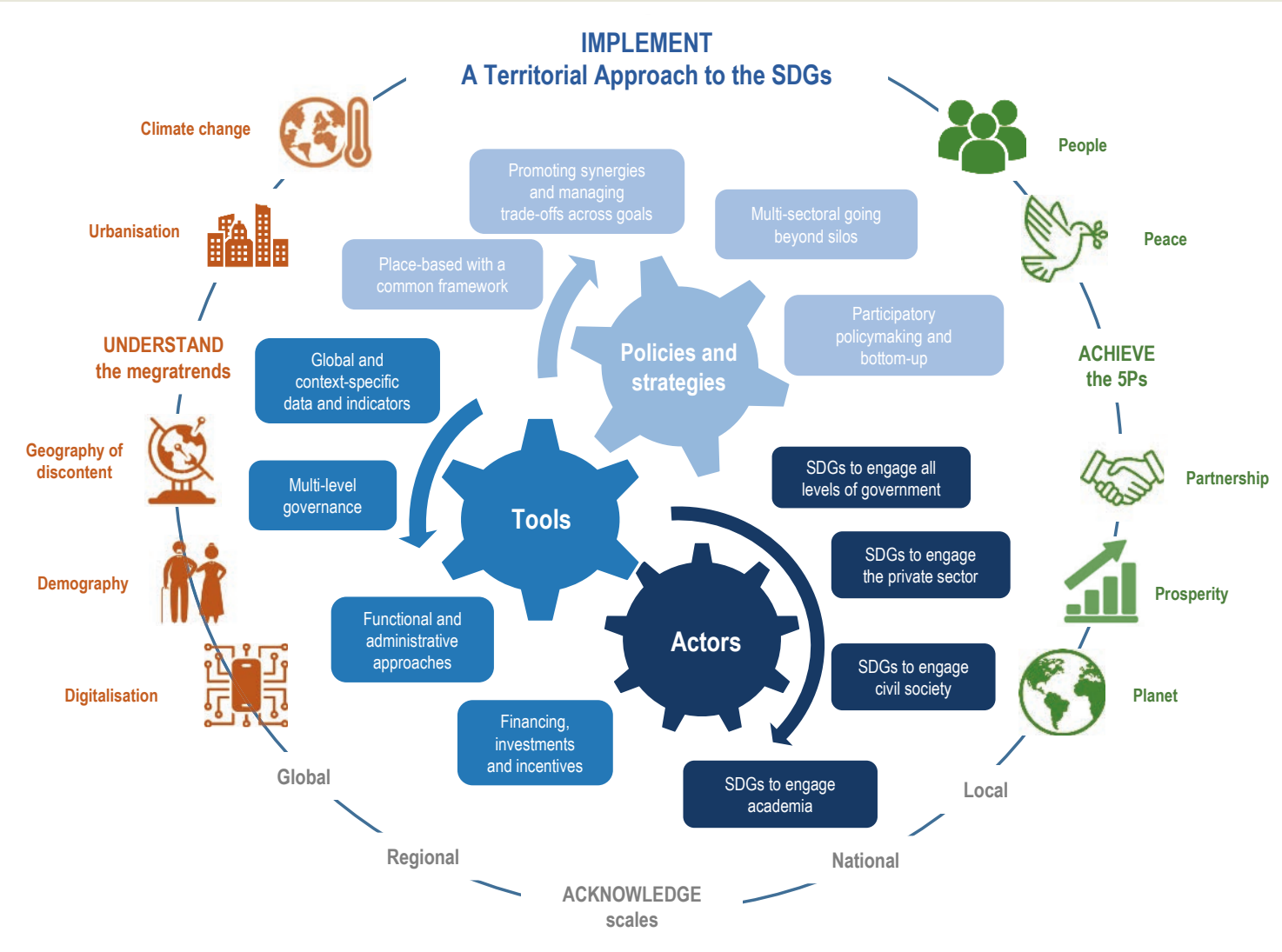

Source: OECD (2020[10]), A Territorial Approach to the Sustainable Development Goals: Synthesis Report, https://doi.org/10.1787/e86fa715-en.; OECD (2019[9]), OECD Regional Outlook 2019: Leveraging Megatrends for Cities and Rural Areas, https://dx.doi.org/10.1787/9789264312838-en.

Bonn has seized the SDGs as a means to upscale its commitment towards sustainability. The SDGs are considered a strategic tool that provides a holistic framework to align incentives and policies related to its key priorities, contributing to making Bonn a continued attractive place to live in the $21^{\text {st }}$ century. The inclusion of social participation and gender as a priority area in the strategy reflects Bonn's broadened vision on sustainability, as these social dimensions had not been explicitly considered in past sustainability policies in Bonn.

The main priority areas and SDGs identified in Bonn's Sustainability Strategy reflect the key challenges of the city, as well as areas in which the city is able to influence and act. As evident from the anchoring of the strategy, the city of Bonn has a key focus on environmental sustainability, with its strategy linked to many environmental plans and policies (Table 1.1). Because of Bonn's position as a sustainability hub for global, national and local actors, global responsibility also features among the top priorities. The 2019 Sustainability Strategy thus includes ambitious goals related to minimising $\mathrm{CO}_{2}$ emissions, providing 
housing for a growing population (including affordable housing) while maintaining the city's green spaces, shifting to low-carbon means of transport and energy, and providing employment for all, especially for lowskilled workers. On the other hand, it also builds on its strategic position as a global hub for a wide range of sustainability actors (Priority Area VI).

Being 1 of 15 pilots in North Rhine-Westphalia (NRW) participating in the national project "Municipalities for Global Sustainability", the city of Bonn received technical support to develop its comprehensive Sustainability Strategy (2019), including from the regional network organisation LAG 21 NRW and the national Service Agency Communities in One World (SKEW) of Engagement Global. Funded through the Federal Ministry for Economic Cooperation and Development (BMZ), the Municipalities for Global Sustainability project provided support to 13 cities and municipalities and 2 administrative districts in NRW over a 2-year period (2016-18) (Bertelsmann Foundation, 2017 $[11]$ ). In Bonn, the Department of International Affairs and Global Sustainability and the Department for Environment, Consumer Protection and Local Agenda co-ordinated the work on the strategy, starting with a baseline study evaluating existing policies, concepts, master plans, projects, council decisions and partnerships in terms of their relevance to the SDGs. Twelve relevant fields of municipal action were first identified, six of which were selected as first priorities for the strategy.

Figure 1.2. The six priority areas in the city of Bonn's Sustainability Strategy

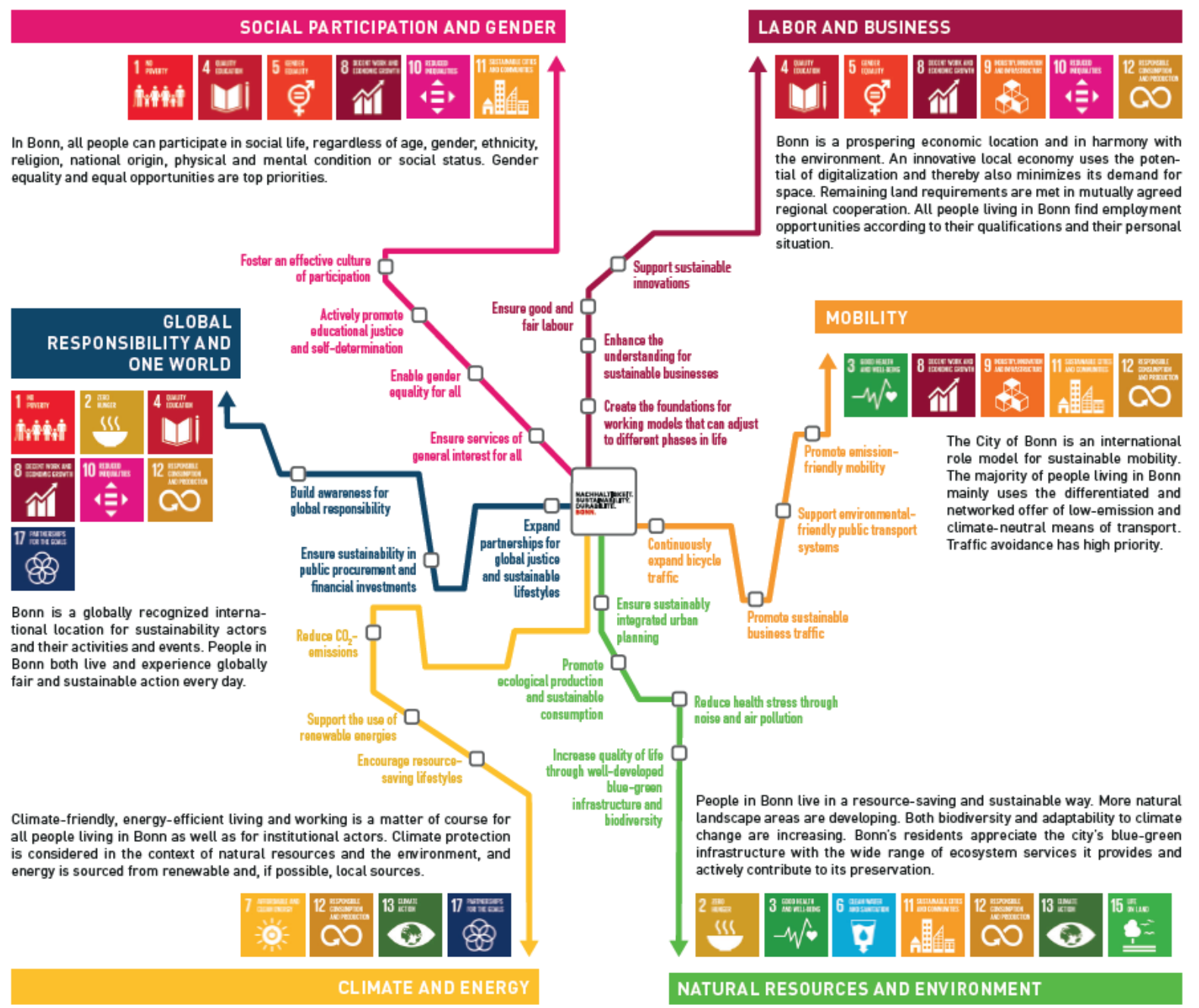

Source: City of Bonn (2018[12]), Sustainability Strategy, Federal City of Bonn - Implementation of the Agenda 2030 in Bonn. Link between SDGs and the Policy of the City. 
The development of Bonn's 2019 Sustainability Strategy contributed to bringing together a wide range of policy areas, measures and operations under one strategy and thus constitutes the first step towards the systematic implementation of SDGs. Examples of such areas or measures include the Master Plan for Energy and Climate, the project "Future Bicycle Mobility" and the Inner City Masterplan, the Bonn Fair Trade Town project and participation in the Covenant of Mayors for Energy and Climate - including its commitment to reduce $\mathrm{CO}_{2}$-emissions by at least $40 \%$ by 2030 . Likewise, many elements in the fields of participation and inclusion were used as a basis to formulate more advanced objectives in the Sustainability Strategy, like the guidelines for citizen participation, the plan for participation of socially vulnerable groups, cross-sectoral social planning and the resolutions to promote accessible housing. Finally, the city administration's "fair procurement" practice is a key element relevant to the strategy, whereby Fair Trade principles $^{3}$ are applied in public procurement. The city administration has signed a resolution to only serve Fair Trade goods in official meetings and has procured Fair Trade workwear for all employees of the Office for Green Spaces and Parks. Nevertheless, despite the many plans and initiatives that exist, implementation has proven to be challenging in the past. It thus remains to be seen whether better integration under a common local sustainability strategy can help to solve such bottlenecks.

\section{Table 1.1. Key priority SDGs for the city of Bonn from the OECD Survey}

\begin{tabular}{|c|c|c|}
\hline & Priority SDGs & Rationale \\
\hline : & SDG 7: Affordable and clean energy & $\begin{array}{l}\text { Considering a projected population growth of around } 20000 \text { inhabitants by } 2025 \text { and } \\
\text { the fact that } 40 \% \text { of } \mathrm{CO}_{2} \text { emissions are estimated to come from private households, } \\
\text { clean energy and reduced } \mathrm{CO}_{2} \text { emissions are central to Bonn's local Sustainability } \\
\text { Strategy. }\end{array}$ \\
\hline & SDG 11: Sustainable cities and communities & $\begin{array}{l}\text { SDG } 11 \text { is a cross-cutting priority goal to mainstream sustainable development } \\
\text { throughout Bonn's institutions and structures. It also has political importance in light of } \\
\text { the mayor's role in fora such as ICLEI (Local Governments for Sustainability) and } \\
\text { Bonn's position as federal and Germany's UN City. }\end{array}$ \\
\hline $12=$ & $\begin{array}{l}\text { SDG 12: Responsible production and } \\
\text { consumption }\end{array}$ & $\begin{array}{l}\text { This priority goal reflects Bonn's role as Fair Trade City and aspiration towards global } \\
\text { responsibility, promoting responsible production and consumption both at home and } \\
\text { abroad. This cross-cutting goal also has possible positive effects on SDG } 3 \text { (Health), } \\
8 \text { (Decent Work), } 13 \text { (Climate Protection) and } 15 \text { (Life on Land). }\end{array}$ \\
\hline (3) & SDG 13: Climate action & $\begin{array}{l}\text { Building on the city's long-term commitment to climate protection, as well as a location } \\
\text { for global climate action, SDG } 13 \text { plays an important role in the city's continued efforts } \\
\text { to reduce } \mathrm{CO}_{2} \text { emissions. }\end{array}$ \\
\hline 17 & SDG 17: Partnerships for the goals & $\begin{array}{l}\text { With over two decades of partnerships with the Global South and participation in } \\
\text { international networks (e.g. ICLEI, Covenant of Mayors for Energy and Climate), Bonn } \\
\text { is committed to continuing peer learning and exchange, particularly on topics such as } \\
\text { water, energy and waste management. }\end{array}$ \\
\hline
\end{tabular}

Note: The survey, based on an OECD questionnaire, was filled by representatives from the city of Bonn and vetted by the municipal committee responsible for the Sustainability Strategy.

Source: Responses by the city of Bonn to the OECD SDG Survey (2018).

\section{Institutionalising the Sustainability Strategy: Main functions, budgeting process and reporting}

Three main functions and corresponding institutional bodies were put in place to develop the Sustainability Strategy through a multi-stakeholder process. First, a project working group with around 25 representatives from civil society and local businesses, academia and politicians was set up to provide input to the drafting of the strategy. This group also rated the priorities identified as a basis for the strategy. Second, a steering group including 12 members from all the departments in the city administration ensured an integrated analysis and drafting of the strategy contents. Finally, a co-ordination group, including staff from the 
Department of International Affairs and Global Sustainability (DIAGS) and the Department of Environment, Consumer Protection and Local Agenda, acted as a focal point for the project and co-ordinated the drafting of its content.

This governance structure was then adjusted for the implementation of the 2019 Sustainability Strategy, under the leadership of the mayor, consolidating the steering group and introducing a new expert committee on sustainability. Institutions such as Bonnorange (the municipal company responsible for the city's waste management) and SWB (a public transportation company), joined the municipal committee. Moreover, the city created an expert committee on sustainability, including politicians, academia, civil society, private sector, among others, to provide advice to the city council on how to improve sustainability. The latter group is action-oriented and focuses on identifying lighthouse innovative projects. It is led by the mayor and meets at least once a year.

Lessons learnt through the strategy development helped identify implementation challenges. For example, bringing on board different departments in the city administration and ensuring political support for all parts of the strategy was time-consuming and required important co-ordination efforts; the initially planned project period of 1.5 years had to be extended to cater for this prolonged consultation and harmonisation processes. After 2.5 years, the strategy was finally adopted by the city council (February 2019). While drawing on previous experiences from the Local Agenda 21 helped to facilitate the strategy development process, continued efforts are needed to raise internal awareness in the city administration around SDGrelated topics. The project co-ordination team has therefore organised actions like lunchtime seminars, both to present the strategy itself and its implementation measures and to discuss practical issues like bicycle traffic.

\section{A need to link the 2019 Sustainability Strategy to the municipal budget}

A major challenge underlying the strategy implementation is that it has not been linked to budget decisions. Some of the measures are funded through ongoing activities, such as education on the SDGs, Fair Trade City activities, participation in the Bio-Cities Network while this is also the case for a substantial number of measures in the field of climate and energy. Other measures will need separate funding decisions on a case-by-case basis by the city council. These include, among others, ambitious measures in the field of mobility. Some financial challenges are thus expected in this regard, particularly in light of limited financial flexibility resulting from the ongoing fiscal consolidation process. This latter further implies that each two-year budget has to be approved by the superior district government in Cologne, aiming at a balanced budget by 2021 .

For the new budget period 2021-22, the city of Bonn envisages to roll-out impact-oriented budgeting with a particular view to sustainability criteria. A new budgeting tool will help to measure the impact of public investment on achieving the objectives in the sustainability field. The tool is structured around four key steps: i) impact (what do we want to achieve?); ii) performance (what services must we provide?); iii) processes (how do we have to provide our services?); and iv) allocation of means (what means do we want to use?). The city is implementing a pilot project with this methodology in three departments, including the Department of International Affairs and Global Sustainability. The tool is implemented through a webbased application (Axians Intercommunal Comparison Systems, IKVS). The Municipal Sustainability Budget under LAG 21 NRW, which pursues the goal of presenting the Bonn Sustainability Budget 202122, will in selected thematic areas link to impact-oriented goals of the IKVS web application.

\section{Tracking progress of Bonn's Sustainability Strategy}

Bonn has been reporting on sustainability indicators since the early 2000 s, starting with a report covering 20 indicators for the period 2002-04. The first comprehensive sustainability report was produced in 2006, followed by three reports since then, the latest of which covers 2016-18. The fact that some indicators 
have been in place since 2002, allows the city to analyse sustainability trends over time to inform local policies. The set of indicators has further been expanded to include additional indicators in order to reflect the 17 Sustainable Development Goals. The 2016-18 Sustainability Report includes 55 indicators and applies a traffic light system to visualise whether trends are moving in a desirable direction.

Bonn's sustainability reporting, led by the Local Agenda Office, serves different purposes, including benchmarking, while focusing on measuring indicators that inform about actions relevant to the city administration. As such, indicators for monitoring the Sustainability Strategy implementation will be used alongside additional "headline" SDGs indicators that allow for benchmarking, including those developed by the Bertelsmann Foundation (Box 1.2). Bonn's city administration has been rather reluctant to benchmark performance since different places have different starting conditions, hence comparisons risk generating negative perception of already disadvantaged places.

The city of Bonn has also implemented an innovative tool to track local public action linked to the SDGs. The SDG Tool was set up within the City Council Information System in October 2019, allowing staff to indicate SDG-relevant documents and to specify to which SDGs actions submitted for council information and decision pertain. The municipal board and steering group of the Strategy are promoting the use of this tool, however a strategy to implement it fully and train staff accordingly still has to be developed.

\section{Box 1.2. Bertelsmann Foundation's SDG Indicators for German Municipalities}

To facilitate the monitoring progress towards the SDGs at the municipal level, the Bertelsmann Foundation has supported the joint initiative "SDG Indicators for Municipalities", involving a wide range of relevant partners. ${ }^{4}$ Through the initiative, a catalogue currently including 47 indicators has been developed for German municipalities to measure their progress toward the SDGs. The indicators included are outcome- and impact-oriented, as opposed to process-oriented indicators.

The catalogue was developed through a four-step process starting with an "SDG relevance check". This relevance check first involved breaking down the 169 official SDG targets into 220 targets and subtargets. The next questions were used to find out whether the target (or sub-target) corresponds to a major challenge for German municipalities, and whether municipalities can make contributions towards them within the scope of their mandated tasks. For the 126 targets and sub-targets that passed the relevance check, the initiative identified and described relevant indicators. To identify suitable indicators, around 600 indicators from catalogues from the UN, Eurostat, national, Länder and municipal levels were collected, which led to the selection of the current 47 final indicators based on 4 criteria: i) data quality; ii) data availability; iii) function (i.e. whether it is an input, output, outcome or impact indicator); and iv) validity (how well it represents the target or sub-target). As a next step, indicator parameters derived from official statistics were analysed, to detect at which administrative level the indicators are available. The analysis found that data availability declined at lower administrative levels. The final indicators included in the catalogue, therefore, apply to municipalities with more than 5000 inhabitants.

Results are currently disseminated through various means. One is the publication of the detailed indicator catalogue describing the 47 indicators included so far, designed as an advisory product made available to all cities and municipalities. The indicators and data are also disseminated through various online portals, the most recent one being www.sdg-portal.de, ${ }^{5}$ where municipalities can tailor and download reports and compare themselves to peers in terms of individual indicators (i.e. not the overall progress towards the SDGs or an SDG index).

Out of the current 47 indicators identified by the Bertelsmann Foundation, 17 are already used in Bonn's sustainability reporting, whereas 10 indicators will require more expertise and adaptation in order to be adopted. One example is renewable energy, where the indicator on the production of wind energy was 
perceived not to be relevant for Bonn due to its limited potential for wind energy compared to solar energy. The adaptation of indicators to fit the context of Bonn is work in progress.

The Bertelsmann Foundation plans to further develop the indicator catalogue for municipalities as well as the SDG portal (www.sdg-portal.de / www.sdg-portal.org).

Source: Bertelsmann Foundation (2018[13]), SDG Indicators for Municipalities - Indicators for Mapping Sustainable Development Goals of the United Nations in German Municipalities (Summary),

https://www.bertelsmann-stiftung.de/fileadmin/files/Projekte/Monitor_Nachhaltige_Kommune/MNK_SDG_Summary.pdf.

\section{Bonn's commitment to climate action and global responsibility}

Bonn's commitment to sustainable development dates back to the Rio Conference in 1992 and its early engagement with Local Agenda 21. In 1997, a political committee and a dedicated office to support the implementation of the Local Agenda action plan were set up to raise awareness about sustainable development among local citizens and share experiences between cities in Germany and Europe. Currently, the office leads the efforts towards the 2030 Agenda and co-ordinates the city's sustainability reporting, which is a strong feature in Bonn's sustainable development tradition. The SDGs provide an inward-looking function for the city of Bonn, which has been a certified Fair Trade Town since 2010 and has been raising awareness about sustainable production and consumption in the city, including through public procurement.

Bonn also has a longstanding commitment to global partnerships with other municipalities, starting in 1992 with Ulan Bator in Mongolia and 1993 with Minsk in Belarus. In 1999 the city council adopted a "strategy for international cooperation" that focuses on project partnerships with cities in developing and emerging economies, in particular on environmental education and waste management in Cape Coast, Ghana (since 2008), sustainable tourism in Bukhara, Uzbekistan (since 2003), the promotion of eco-efficiency in La Paz, Bolivia (since 2002), and science exchange and cultural meetings with the city of Chengdu, China (since 2000). The focus of the cooperation is on knowledge exchange, particularly in areas such as sustainable urban development, environmental protection, cultural cooperation and youth exchange. While Bonn's global commitments were largely treated in isolation in the era of the Millennium Development Goals, the 2030 Agenda has led to their full-fledged integration in the city's holistic Sustainability Strategy (2019).

Prior to developing its Sustainability Strategy (2019), the city already signed a resolution called "The 2030 Agenda for Sustainable Development: Building Sustainability at the Local Level" in 2016. This resolution, drafted by the Association of German Cities and the Council of European Municipalities and Regions (CEMR), has around 140 signees in Germany. It calls for increased involvement by local authorities in the development of strategies for achieving the SDGs and outlines what cities and municipalities can do to contribute to the 2030 Agenda. For example, it suggests activities such as strengthened city-to-city partnerships, working together with businesses and schools, as well as harnessing the potential of migrants to act as "bridge-builders". 


\section{References}

Bertelsmann Foundation (2018), SDG Indicators for Municipalities - Indicators for Mapping Sustainable Development Goals of the United Nations in German Municipalities (Summary), https://www.bertelsmannstiftung.de/fileadmin/files/Projekte/Monitor Nachhaltige Kommune/MNK SDG Summary.pdf.

Bertelsmann Foundation (2017), Monitor Nachhaltige Kommune Bericht 2017 [Monitor: Sustainable Municipality Report 2017], https://www.bertelsmannstiftung.de/fileadmin/files/Projekte/Monitor Nachhaltige Kommune/MonitorNachhaltigeKomm une Bericht2017.pdf.

City of Bonn (2020), Business City, https://www.bonn.de/microsite/en/business-andscience/business-in-bonn/business-city.php.

City of Bonn (2020), Innovative Knowledge City, https://www.bonn.de/microsite/en/business-andscience/business-in-bonn/innovative-knowledge-city.php.

City of Bonn (2020), Jahreswirtschaftsbericht 2019 [Annual Economic Report 2019], https://www.bonn.de/medien-global/amt-03/Jahreswirtschaftsbericht 2019.pdf.

City of Bonn (2018), Sustainability Strategy, Federal City of Bonn - Implementation of the Agenda 2030 in Bonn. Link between SDGs and the Policy of the City.

City of Bonn (2017), Bonn - Federal City and Centre of International Cooperation, Mayor of the City of Bonn/Press Office.

Information Service - Federal City of Bonn (2017), The Berlin/Bonn Act and the Compensation Agreement, https://www.bonn.de/rat verwaltung buergerdienste/presseportal/daten und fakten/index.ht ml?lang=en.

Kushner, J. (2001), "Planning for downsizing: A comparison of the economic revitalization initiatives in American communities facing military base closure with the German experience of relocating the national capital from Bonn to Berlin", The Urban Lawyer, Vol. 33/1, pp. 119146, https://www.jstor.org/stable/27895285.

OECD (2020), A Territorial Approach to the Sustainable Development Goals: Synthesis report, OECD Urban Policy Reviews, OECD Publishing, Paris, https://dx.doi.org/10.1787/e86fa715en.

OECD (2019), OECD Regional Outlook 2019: Leveraging Megatrends for Cities and Rural Areas, OECD Publishing, Paris, https://dx.doi.org/10.1787/9789264312838-en.

The University of Bonn (2019), Zahlen und Fakten [Facts and Figures], https://www.unibonn.de/die-universitaet/ueber-die-universitaet/die-universitaet-bonn-in-zahlen-und-fakten (accessed on 25 May 2020).

UN Bonn Information (2018), UN Bonn - Shaping a Sustainable Future, UN Bonn Information/UN Campus. 


\section{Notes}

${ }^{1}$ See: www.unbonn.org for more information.

2 See: https://sdgactioncampaign.org.

3 The social criteria applied for Fair Trade products are: health, environment and safety standards; compliance with regular working hours; respect for freedom of association; socially responsible production; credible evidence.

${ }^{4}$ Partners include: Bertelsmann Stiftung, the Federal Institute for Research on Building, Urban Affairs and Spatial Development, the German County Association, the Association of German Cities, the German Association of Towns and Municipalities, the German Institute of Urban Affairs, Engagement Global and the Council of European Municipalities and Regions / German Section. While the national statistics office has participated in discussions, they are not an official partner of the initiative.

${ }^{5}$ See also: www.wegweiser-kommune.de and www.keck-atlas.de. 



\section{Sustainable development} challenges and opportunities in Bonn, Germany

The achievements of the FUA of Bonn on the SDGs are similar to the overall average of functional urban areas in OECD countries. The FUA's results are particularly good in the areas of healthcare, innovation and accessibility of green spaces, while policy areas with space for improvement include transport, air pollution and old-age poverty. The SDGs provide a framework to build on Bonn's good performance and explore further the interlinkages between key policy areas such as climate and air quality, transport and sustainable mobility, business development, clean energy, affordable housing and the emerging of old-age poverty. 


\section{Measuring the distance to the SDGs in Bonn, Germany}

The following analysis of the FUA of Bonn's SDGs achievements and remaining challenges, based on the OECD localised indicator framework (Box 1.1), uses the structure of the five critical dimensions of the 2030 Agenda (people, prosperity, planet, partnership and peace) (Figure 2.1). It is based on a selection of 33 indicators covering 14 of the 17 SDGs. ${ }^{1}$ Further information on the methodology of the assessment can be found in Box 2.1. The analysis also integrates complementary data to the OECD indicator framework on the performance of the city of Bonn within its administrative boundaries, which were provided by the city of Bonn in its 2019 Sustainability Report (City of Bonn, 2019 $\left.{ }_{[1]}\right)$ (Tables 2.2, 2.4, 2.6 and, 2.8).

Figure 2.1. The 17 Sustainable Development Goals

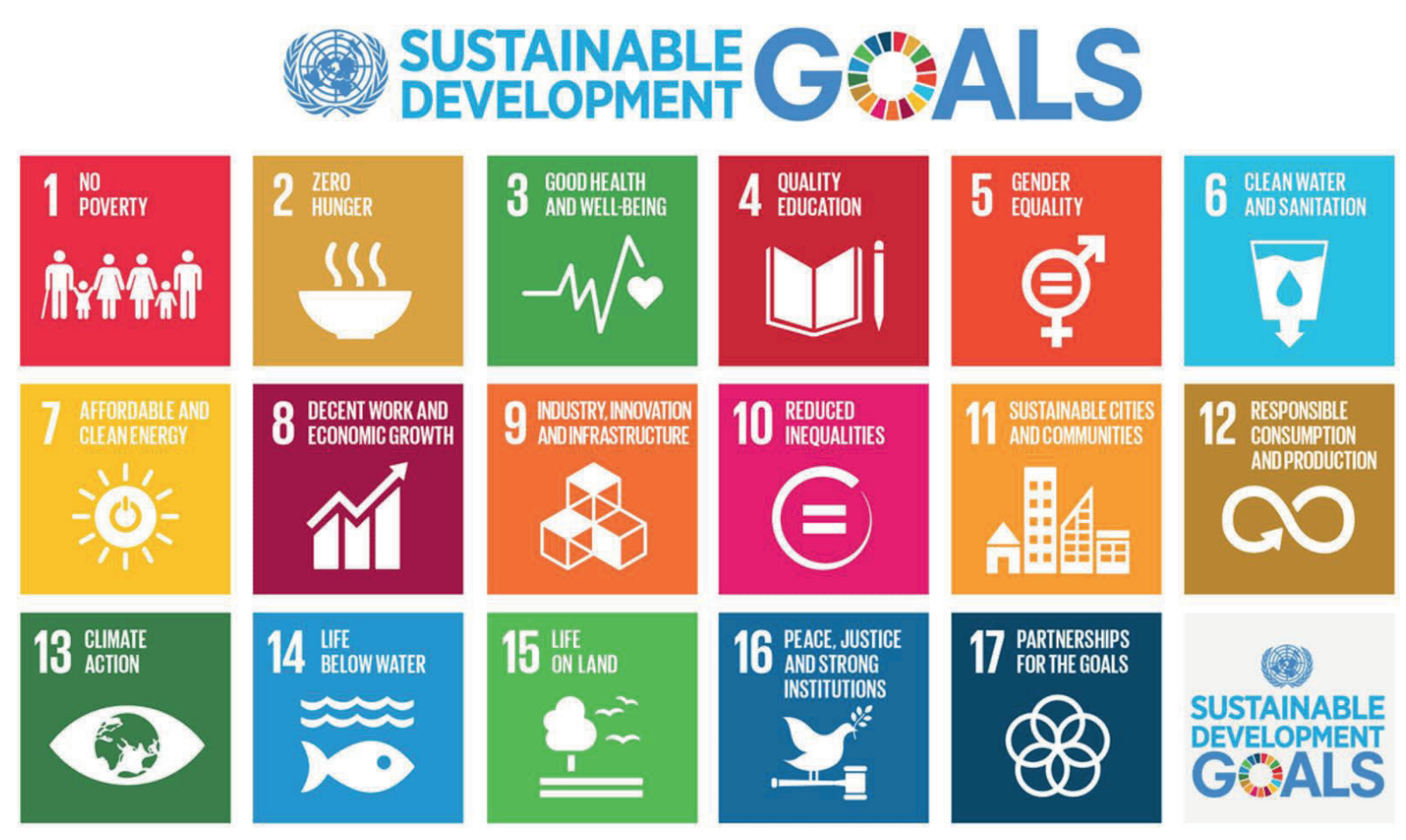

Source: UN Sustainable Development Knowledge Platform (2020[2] ), Sustainable Development Goals, https://sustainabledevelopment.un.org/ ?menu=1300.

Box 2.1. OECD methodology for measuring cities' and regions' distance to the SDGs

The OECD has developed a framework to localise the SDG targets and indicators and measure the distance of regions and cities to each of the 17 SDGs. This consensual, comparable and standardised framework allows to benchmark performances within countries and across regions and cities to support public action across levels of government.

In the context of OECD countries, around 105 out of the 169 SDG targets have been identified as very relevant for regions and cities. Through an extensive literature review and expert consultation, the 169 SDG targets from the UN indicator framework have been classified by their level of relevance for 
subnational levels of government (place-relevant) and advanced economies (OECD-relevant). Subsequently, a subset of these SDG targets has been selected based on its applicability to the context and specificities of OECD countries. The result is a selection of 105 SDG targets and 135 indicators for OECD regions and cities (also referred to as the "subnational SDG targets").

With its 135 indicators, the OECD localised framework covers at least 1 aspect of each of the 17 SDGs for both regions and cities. Nevertheless, the coverage in terms of indicators and targets is higher for regions than for cities. Currently, 56 indicators (covering $32 \%$ of the subnational SDG targets) are available for cities with more than 250000 inhabitants in OECD and partner countries. Although the set of indicators aims to cover the broad spectrum of all 17 SDGs, the coverage in terms of indicators also varies widely across SDGs.

In order to evaluate the achievements of a city or region on the SDGs, the OECD localised framework normalises the SDGs indicators from 0 to 100 - where 100 is the suggested end-value of an indicator to be achieved by 2030 - and aggregates headline indicators that belong to the same SDG to provide an index score towards each of the 17 SDGs. The distance to the target or goal is the number of units the index needs to travel to reach the maximal score of 100 (Figure 2.3).

\section{Selection of indicators used to assess the city of Bonn's achievements in reaching the SDGs}

It is worth noting that the data used in the OECD localised indicator framework refers to the functional urban area (FUA) of Bonn, which goes beyond the administrative boundaries of the city of Bonn (see Box 2.2 for more information). The indicators of the OECD localised indicator framework used for the analysis of the FUA of Bonn were chosen based on the availability of data for the metropolitan area of Bonn and a context-relevance assessment of the indicators conducted by the city's representatives. Such assessment consisted in a survey on the different SDGs indicators proposed by the OECD whereby the representatives of the city of Bonn assessed how relevant the indicator is to help measure the SDGs at the local level in their city (from 0 to 5 ; where 0 stands for "Not relevant" and 5 stands for "Very relevant"). The most relevant indicators were then prioritised for this report. However, the analysis also considers some indicators with a lower relevance rating to provide complementary information on specific policy areas.

In addition to the indicators of the OECD localised indicator framework, this chapter also considers complementary, city-specific indicators used by the city of Bonn (administrative boundaries) itself to track progress with the SDGs. As part of its Sustainability Strategy and reporting, the city of Bonn currently collects a total of 55 indicators in the four key categories: i) well-being; ii) social justice; iii) environmental quality and resource efficiency; and iv) economic efficiency. While Bonn's city-specific indicators only refer to the administrative city of Bonn, the indicators of the OECD localised framework consider the entire FUA of Bonn. Since the city of Bonn's indicators do not necessarily coincide with the OECD framework, they are not comparable to other FUAs and the OECD average. Nevertheless, they provide useful information about the progress on the SDGs in the administrative city of Bonn.

Source: OECD (2020[3]], A Territorial Approach to the Sustainable Development Goals: Synthesis Report, https://doi.org/10.1787/e86fa715en; OECD (2019[4]]), Functional Urban Areas - Germany, https://www.oecd.org/cfe/regional-policy/Germany.pdf. 


\section{Box 2.2. Definition of functional urban areas (FUAs)}

The OECD and the European Commission have jointly developed a methodology to define functional urban areas (FUAs) in a consistent way across countries. Using population density and travel-to-work flows, a FUA consists of a densely inhabited city and of a surrounding area (commuting zone) whose labour market is highly integrated with the city. The ultimate aim of the EU-OECD approach to functional urban areas is to create a harmonised definition of cities and their areas of influence for international comparisons as well as for policy analysis on topics related to urban development.

In that context, a city is defined as a local administrative unit (i.e. LAU for European countries, such as the municipality, local authorities, etc.) where at least $50 \%$ of its population lives in an urban centre. An urban centre is defined as a cluster of contiguous grid cells of $1 \mathrm{~km}^{2}$ with a density of at least 1500 inhabitants per $\mathrm{km}^{2}$ and a population of at least 50000 inhabitants overall. Urban centres are defined using the population grid from the Global Human Settlement Layer database, referred to circa 2015. The commuting zone is composed of the local administrative units for which at least $15 \%$ of their workforce commute to the city. Commuting zones of the functional areas are identified based on commuting data (travel from home-to-work). Commuting data are also used to define whether more than one city share the same commuting zone in a single polycentric functional urban area.

The FUA of Bonn has a population of around 925000 people. More precisely, the FUA of Bonn goes beyond the administrative city of Bonn and includes the surrounding and inter-connected 19 municipalities of the Rhein-Sieg-Kreis, namely Alfter, Bad Honnef, Bornheim, Eitorf, Hennef (Sieg), Königswinter, Lohmar, Meckenheim, Much, Neunkirchen-Seelscheid, Niederkassel, Rheinbach, Ruppichteroth, Sankt Augustin, Siegburg, Swisttal, Troisdorf, Wachtberg and Windeck.

\section{Figure 2.2. Functional Urban Area of Bonn}

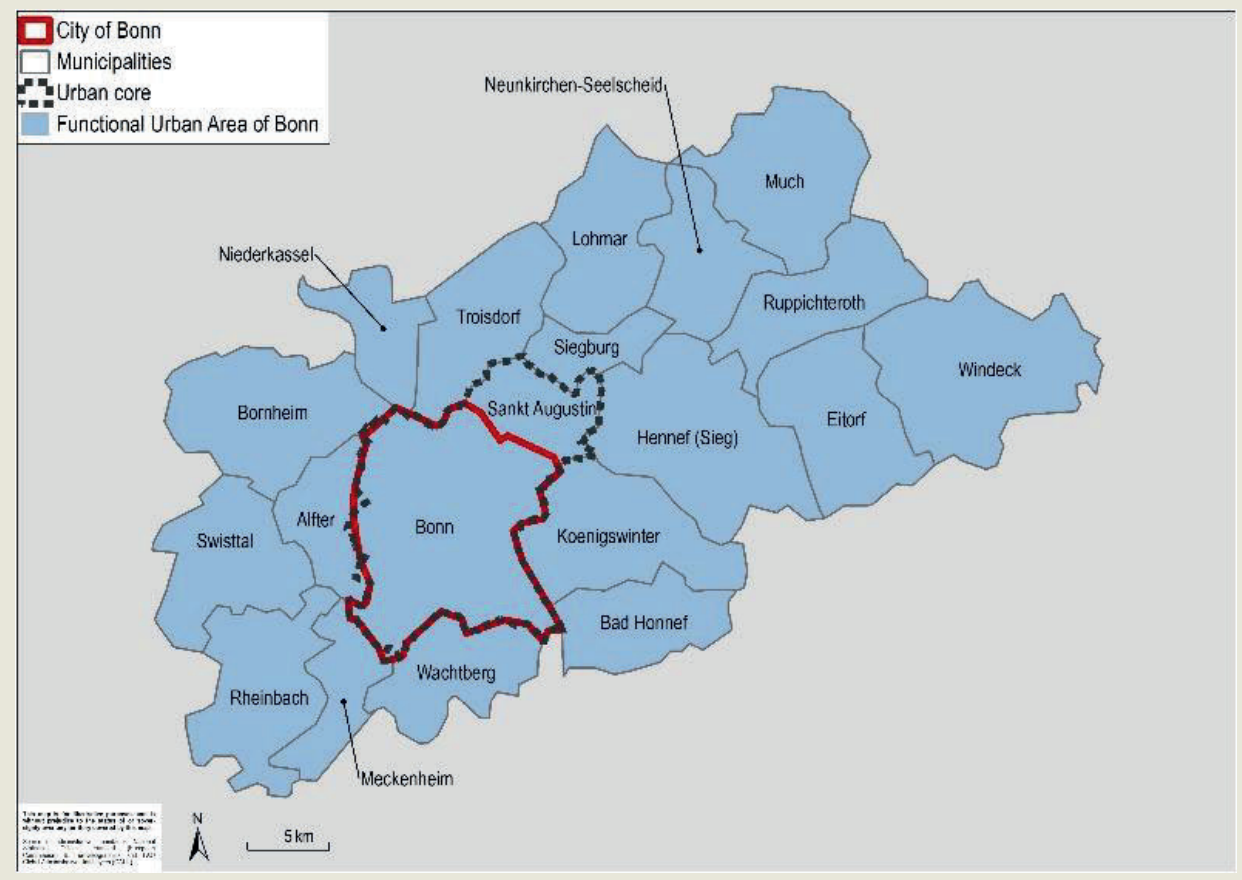

Source: OECD (2019[4] $)$, Functional Urban Areas - Germany, https://www.oecd.org/cfe/regional-policy/Germany.pdf. 
Figure 2.3. FUA of Bonn and the SDGs - Distance to the end values

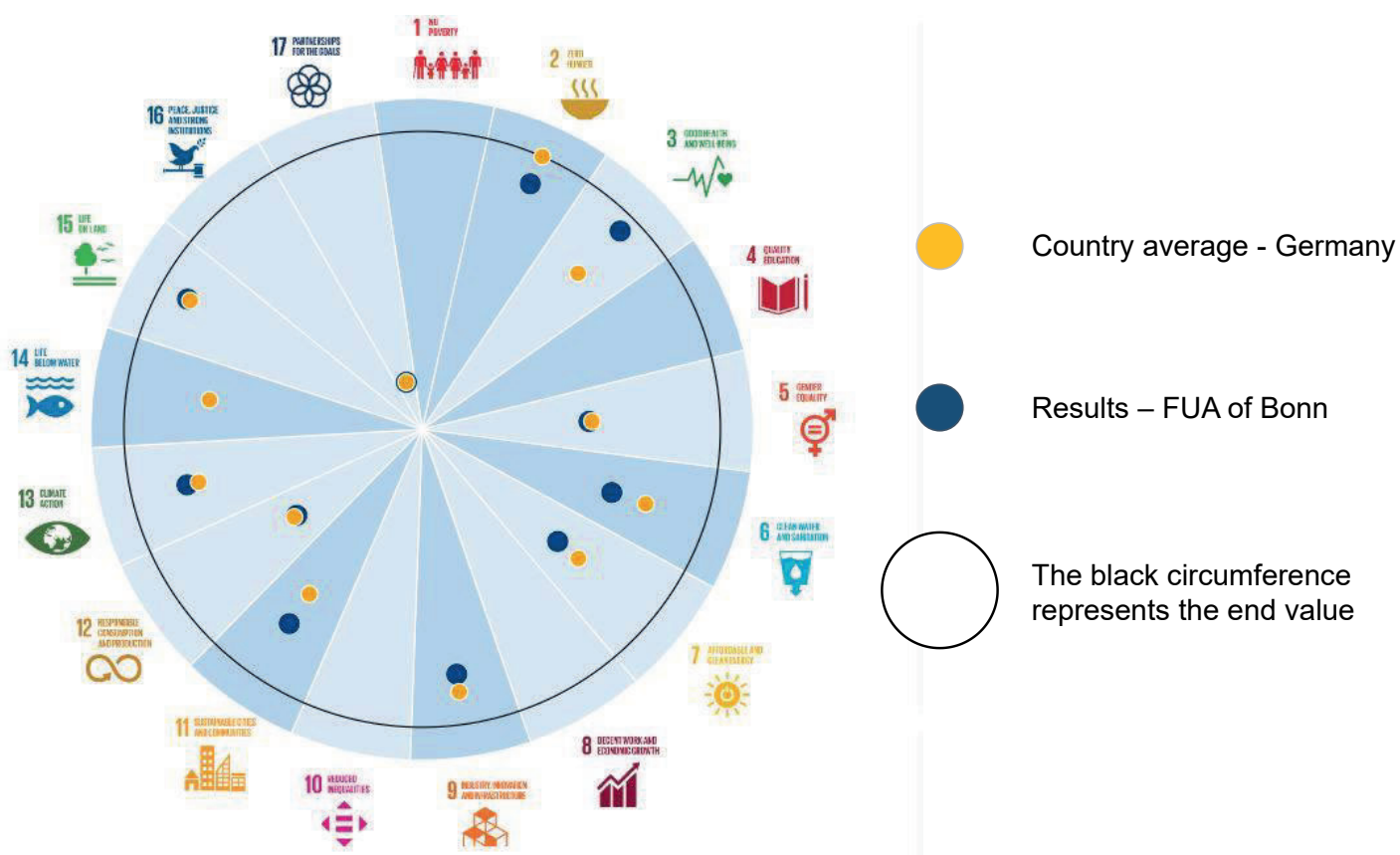

Note: Index from 0 to 100 (100 is the end value: black circumference); Blue dot: FUA of Bonn's result; Yellow dot: Country average of German FUAs of more than 250000 people, for more details about the methodology to build SDG indexes see OECD (2020[3]).

Source: OECD (2020[5]), Measuring the Distance to the SDGs in Regions and Cities (visualisation tool), http://www.oecd-local-sdgs.org/ (accessed on 12 May 2020)

Overall, the FUA of Bonn's performance towards the SDGs is very similar to the average of all OECD FUAs. The FUA's results are particularly good in the areas of healthcare, mortality, innovation and accessibility to green spaces. Policy areas where the FUA of Bonn has space for improvement compared to other OECD FUAs and the end values set for 2030 are clean energy, transport and pollution levels. Out of the 33 indicators of the OECD localised indicator framework, the FUA of Bonn ranks among the top 25\% of OECD FUAs in 8 of the indicators. On the other hand, the FUA also ranks among the bottom $25 \%$ of OECD FUAs in 6 of the indicators. Taking the average of all indicators, Bonn performs better than $52 \%$ of OECD FUAs.

\section{Dimension People: Good health is a key strength while old-age poverty is an emerging challenge}

Spotlight on the OECD Localised Indicator Framework - FUA indicators

Table 2.1. OECD indicators used to assess the dimension People in the FUA of Bonn

\begin{tabular}{|c|c|}
\hline SDG & Indicator \\
\hline \multirow{3}{*}{ 필 } & Percentage of people with access to at least 1 food shop within 15 minutes of walking \\
\hline & Change in cropland (from 1992 to 2015, percentage points) \\
\hline & Cropland as a percentage of the total area in 2015 \\
\hline \multirow{2}{*}{$\sqrt{3=}$} & Infant mortality rate (number of deaths of children one-year-old or younger per 1000 live births) \\
\hline & Transport-related mortality rates (deaths per 100000 people) \\
\hline
\end{tabular}




\begin{tabular}{|c|c|}
\hline & Percentage of people with access to at least 1 hospital within 20 minutes of driving \\
\hline & Percentage of people with access to at least 1 school within 15 minutes of public transport \\
\hline LII & Percentage of people with access to at least 1 school within 20 minutes of walking \\
\hline ब蛋 & Gender gap in employment rate (male-female, percentage points) \\
\hline
\end{tabular}

Source: OECD (2020[3]), A Territorial Approach to the Sustainable Development Goals: Synthesis Report, https://doi.org/10.1787/e86fa715-en, OECD (2020[5]), Measuring the Distance to the SDGs in Regions and Cities (visualisation tool), http://www.oecd-local-sdgs.org/ (accessed on 12 May 2020)

Health, a policy area that is of particular relevance in the context of the global Covid-19 pandemic, is one of the main strengths of the FUA of Bonn. Its infant mortality rate of 2.5 deaths of children one-year-old or younger per 1000 live births is lower than the OECD FUA average and the distance to the end value of 2.2 deaths is relatively small. Beyond that, more than $90 \%$ of people in the FUA of Bonn have access to at least 1 hospital within a 20-minute drive. In this indicator, the FUA of Bonn has already reached the end value of $88.5 \%$. Nevertheless, in more than $40 \%$ of OECD FUAs, an even larger share of the population has access to at least 1 hospital within 20 minutes of driving, which is partially related to the fact that FUAs covered by this indicator are mainly Western European FUAs with generally very high accessibility to hospitals. Bonn's FUA shows similarly good results regarding its transport-mortality. Transportation in the FUA Bonn is safer than in the average OECD FUA. The transport-related mortality rate of 2.2 deaths per 100000 people in 2017 is already lower than the end value of 2.8 and the OECD average of close to 4 deaths per 100000 people (Figure 2.4).

Figure 2.4. Transport-related mortality rates - Deaths per 100000 people (2017): Comparison across FUAs

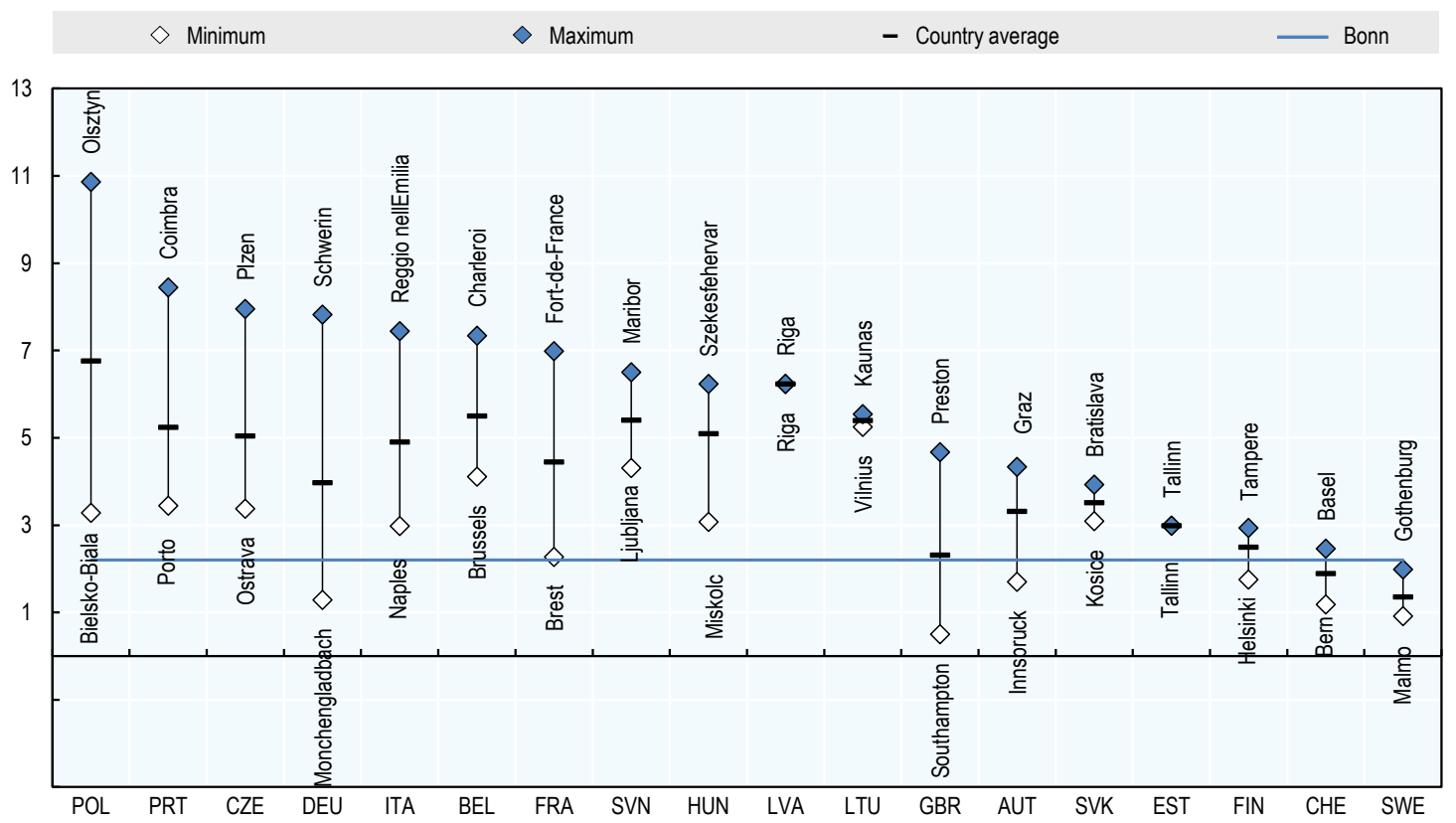

Source: OECD (2020[6]), OECD Regional Statistics (database), http://dx.doi.org/10.1787/region-data-en.

The FUA of Bonn has good access to education facilities, a crucial prerequisite in order to achieve good results in SDG 4 Quality Education. A total of $87 \%$ of the FUA's residents have access to at least 1 school 
within 15 minutes of public transport, while $88 \%$ have access to at least 1 school within 20 minutes of walking. That means that the FUA of Bonn generally shows high proximity between schools and students. Nonetheless, the FUA of Bonn lags behind both the OECD average $(93.4 \%$ for public transport and $90.5 \%$ for walking) and the defined end values ( $94.1 \%$ and $92.4 \%$ respectively) for those 2 indicators.

The FUA of Bonn has experienced a decrease in cropland in the last decades. While food security is not one of the most pressing challenges in OECD countries, sustainable food production systems and the implementation of resilient agricultural practices are important contributory factors on the pathway to a more sustainable agriculture. In that context, the FUA of Bonn has experienced a significant decrease in cropland between 1992 and 2015. In 2015, cropland accounted for around $31 \%$ of the total area of the FUA of Bonn, while the FUA OECD average was $40 \%$. Throughout the $1992-2015$ period, the cropland area in the FUA of Bonn lost close to 6 percentage points of its size, mainly due to a high pressure on land for housing and businesses. In comparison, the average decrease in OECD FUAs was less than 3 percentage points. Overall, only one-fifth of OECD FUAs experienced larger decreases.

The gender gap in employment in the FUA of Bonn is slightly lower than the OECD average. Exhibiting an 8-percentage point gap between the employment rate of men and women, the FUA of Bonn still has some distance to travel to reach the defined end value of $0 \%$ and thus close the gender gap measured within SDG 5 Gender Equality. As of 2017, its gender gap was only slightly smaller than the FUA OECD average of $9 \%$, which means that $45 \%$ of OECD FUAs exhibit smaller gender gaps in employment than the FUA of Bonn.

\section{Spotlight on administrative indicators collected by the city of Bonn}

Table 2.2. Selected Bonn-specific administrative indicators used to assess the dimension People

\begin{tabular}{c|l|l}
\hline SDG & \multicolumn{1}{|c|}{ Indicator } & \multicolumn{1}{c}{ Definition } \\
\hline Childcare facilities for children under three & $\begin{array}{l}\text { Places available in nurseries and day care facilities per } 100 \\
\text { children aged } 0 \text { to under } 3 \text { years }\end{array}$ \\
\hline Childcare facilities for children from three to & $\begin{array}{l}\text { Places available in childcare facilities per } 100 \text { children aged } 3 \text { to } \\
\text { under } 6 \text { years }\end{array}$ \\
\hline under six years & $\begin{array}{l}\text { Proportion of recipients of basic income support aged } 65 \text { and over } \\
\text { as a percentage of the total population aged } 65 \text { and over }\end{array}$ \\
\hline
\end{tabular}

Source: City of Bonn (2019 $\left.{ }_{[1]}\right)$, Nachhaltigkeitsbericht der Stadt Bonn (2016-2018) [Sustainability Report of the City of Bonn (2016-18)], https://www.bonn.de/themen-entdecken/umwelt-natur/nachhaltigkeitsbericht.php.

Old-age poverty is an increasing challenge for the city of Bonn. In view of the demographic change and a larger share of the elderly population (Figure 2.5), old-age poverty will become one of the crucial social policy issues in many industrialised countries with a particular impact on the achievements of SDG 1 No Poverty. In the city of Bonn, the proportion of recipients of basic income support aged 65 and over as a percentage of the total population aged 65 and over has been constantly growing in recent years. In 2006, the share was 3.8\%, before surpassing the 5\% threshold in 2013 and reaching more than $6.3 \%$ in 2018 , thus significantly exceeding the North Rhine-Westphalia state average of $4 \%$ (2017 value). 
Figure 2.5. Demographic structure in the city of Bonn, 2002-18

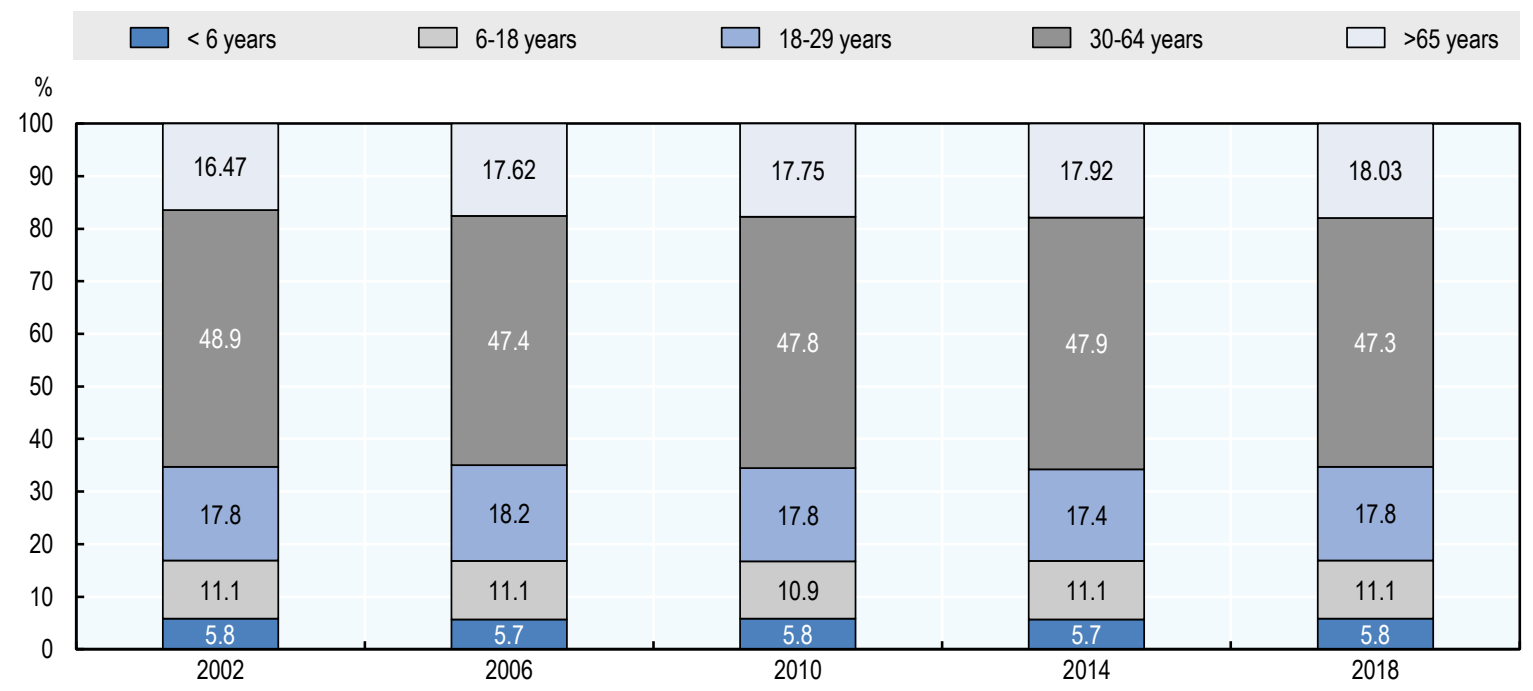

Source: City of Bonn (2019[1]), Nachhaltigkeitsbericht der Stadt Bonn (2016-2018) [Sustainability Report of the City of Bonn (2016-18)], https://www.bonn.de/themen-entdecken/umwelt-natur/nachhaltigkeitsbericht.php.

The city of Bonn places importance on the expansion of childcare services. An adequate supply of childcare facilities for children of different ages is an essential prerequisite for the compatibility of family and career and increases early childhood educational opportunities. The city of Bonn has therefore expanded the availability of places in childcare facilities for young children in recent years thus contributing to SDGs 1, 4 and 5. For instance, the number of places available in nurseries and day care per 100 children aged 0 to under 3 years has increased from $17 \%$ in 2008 to more than $40 \%$ in 2018 (Figure 2.6). In comparison, the average of the state of North Rhine-Westphalia reached $27.2 \%$, whilst the German average was $33.6 \%$. Both are hence way below the achievements of the city of Bonn.

Figure 2.6. Number of places available in nurseries and day care facilities per 100 children aged 0 to under 3 years in the city of Bonn

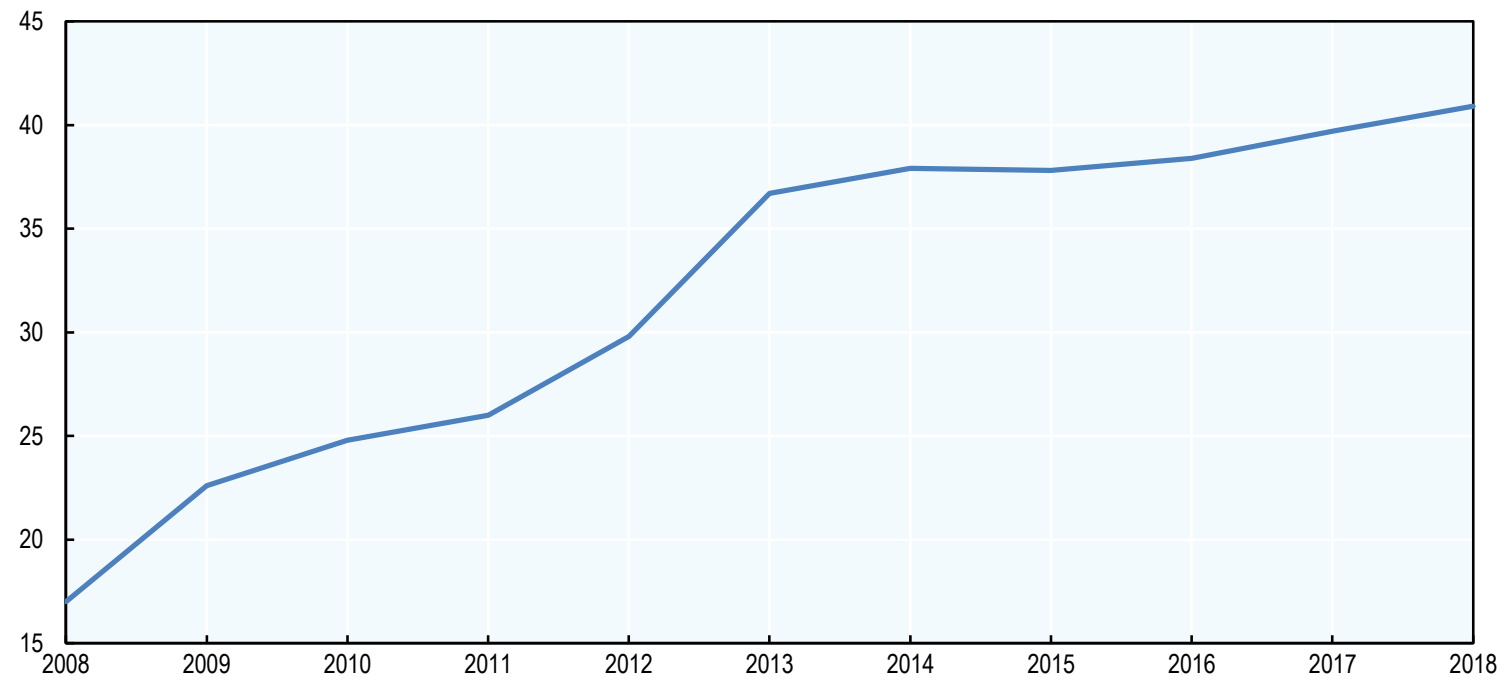

Source: City of Bonn (2019 $[1])$, Nachhaltigkeitsbericht der Stadt Bonn (2016-2018) [Sustainability Report of the City of Bonn (2016-18)], https://www.bonn.de/themen-entdecken/umwelt-natur/nachhaltigkeitsbericht.php. 
The city of Bonn has as many places available in childcare facilities per 100 children aged 3 to under 6 years as there are children in that age group. Going up from 92.5 places in 2008 , the city has constantly reached or surpassed the 100 places threshold since 2014. It thus also surpasses the North RhineWestphalia state average (92 places) and the national average of 93 places. The city aims to reach a value of 102 by 2022 to create a surplus that can cover the growing or future demand for childcare places.

\section{Dimension Planet: Commitment to biodiversity and low emissions, but car usage and waste are pressing issues}

Spotlight on the OECD Localised Indicator Framework - FUA indicators

Table 2.3. OECD indicators used to assess the dimension Planet in the FUA of Bonn

\begin{tabular}{|c|c|}
\hline SDG & Indicator \\
\hline \multirow{2}{*}{6} & Change in water bodies (from 1992 to 2015 , percentage points) \\
\hline & Water bodies as percentage of the total area in 2015 \\
\hline \multirow{2}{*}{$\mathrm{QO}$} & Municipal waste rate (kilos per capita) \\
\hline & Number of motor road vehicles per 100 people \\
\hline \multirow{2}{*}{9} & $\mathrm{CO}_{2}$ emissions per electricity production (in tonnes of $\mathrm{CO}_{2}$ equivalent per gigawatt hours) \\
\hline & $\begin{array}{l}\text { Change in cooling degree-days needed to maintain an average building indoor temperature of } 22 \text { degrees Celsius, from } 1970-1984 \\
\text { to } 2004-18\end{array}$ \\
\hline \multirow{3}{*}{ 垔 } & Change in tree cover (from 1992 to 2015 , percentage points) \\
\hline & Tree cover as a percentage of the total area in 2015 \\
\hline & Terrestrial protected areas as a percentage of the total area \\
\hline
\end{tabular}

Source: OECD (2020[3]), A Territorial Approach to the Sustainable Development Goals: Synthesis Report, https://doi.org/10.1787/e86fa715-en, OECD (2020[5]), Measuring the Distance to the SDGs in Regions and Cities (visualisation tool), http://www.oecd-local-sdgs.org/ (accessed on 12 May 2020)

The FUA of Bonn leads the way in biodiversity protection compared to most OECD FUAs. With more than $60 \%$ of its total area having the status of protected area, its FUA is among the $2 \%$ of OECD FUAs that protect terrestrial areas $^{2}$ the most in OECD countries (Figure 2.7). In comparison, the OECD FUA average only reaches $17 \%$. The FUA of Bonn also already surpasses the end value defined for 2030 of $38 \%$ by far. Beyond that, the FUA of Bonn has expanded its tree cover, which has increased by $0.53 \%$ between 1992 and 2015 , while it has decreased by $0.85 \%$ on average in OECD FUAs. Accordingly, the FUA of Bonn ranks among the $30 \%$ of OECD FUAs with the largest increases in tree cover in addition to the fact that the city already has a larger tree population than the average FUA. Despite these achievements, there remains a gap to the end value set at $2.88 \%$. 
Figure 2.7. Terrestrial protected areas as a percentage of total area (2017): Comparison across FUAs

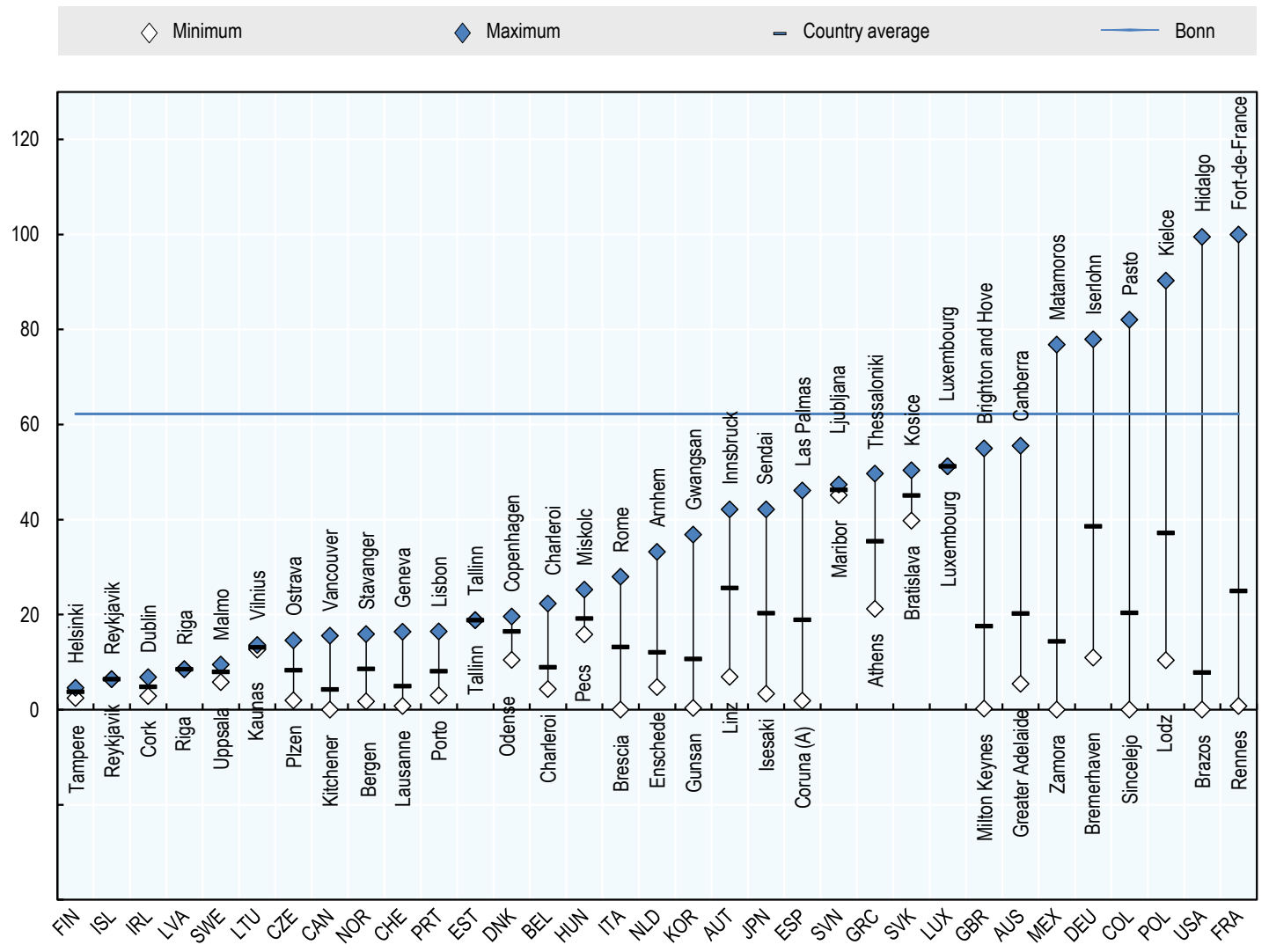

Source: OECD (2020[6]), OECD Regional Statistics (database), http://dx.doi.org/10.1787/region-data-en.

The FUA of Bonn is performing slightly better than the FUA OECD average in SDG 13 Climate Action. For instance, the city emits less $\mathrm{CO}_{2}$ (in tonnes of $\mathrm{CO}_{2}$ equivalent per gigawatt hours) in its electricity production than the average OECD FUA (319 vs. 339 tonnes). This, however, does not imply that the FUA of Bonn is on track to reach the 2030 end value set at 111 tonnes, for which the emissions stemming from its electricity production would need to be cut by almost two-thirds until 2030. In addition, the FUA of Bonn has experienced an increase in average temperatures throughout the last decades. To maintain an average indoor temperature of 22 degrees Celsius, there were close to 10 more cooling-days needed in the 20042018 period compared to the period between 1970 and 1984 (OECD based on Historical Global-Gridded Degree-Day Database). While the number of days is lower than the FUA OECD average of 33 days, it nevertheless points out the remaining efforts needed to contain global warming.

Regarding SDG 12 Responsible Production and Consumption, the residents in the FUA of Bonn produce more waste. In 2017, people in the FUA of Bonn produced on average $470 \mathrm{~kg}$ of waste per capita ${ }^{3}$. In comparison, the end value for 2030 is defined at $306 \mathrm{~kg}$. The FUA Bonn might face challenges to reach the end value by 2030 . Within the city of Bonn, which measures its waste rate as residual waste and bulky waste per capita, households and small enterprises, the per capita waste rate was lower and reached 222 $\mathrm{kg}$ in 2018 following a downward trend since 2016.

In the FUA of Bonn, the share of 49 motor road vehicles per 100 people is significantly higher than the end value of 36. Reaching this value would require changes in transport patterns among the population to reach SDG 12 Responsible Production and Consumption by 2030. When considering only Bonn's 
administrative boundaries, the per capita ratio of motor road vehicles is however lower than in the FUA of Bonn. With 40 motor road vehicles per 100 residents in 2018, the city of Bonn's motor vehicle rate was below both the state average of North Rhine-Westphalia (56.2) and the German average (50.0).

In SDG 6 Clean Water, the FUA of Bonn ranks among the 20\% of OECD FUAs experiencing the largest declines in water bodies. Indeed, the FUA of Bonn registered a decrease in water bodies by -0.11 percentage points between 1992 and 2015 . While that value is not particularly high, it nevertheless points into the opposite direction of the end value, which is supposed to be positive ( 0.17 percentage points). In addition, the share of water bodies as a percentage of the total area in the FUA of Bonn (1.6\%) is already smaller than the FUA OECD average (2.1\%).

\section{Spotlight on administrative indicators collected by the city of Bonn}

Table 2.4. Selected Bonn-specific administrative indicators used to assess the dimension Planet

\begin{tabular}{c|l|l}
\hline \multicolumn{1}{c|}{ Indicator } & \multicolumn{1}{c}{ Definition } \\
\hline & Waste & $\begin{array}{l}\text { Residual waste and bulky waste in the disposal area from private households and small } \\
\text { businesses in kilograms per inhabitant and year }\end{array}$ \\
\hline
\end{tabular}

Source: City of Bonn (2019[1]), Nachhaltigkeitsbericht der Stadt Bonn (2016-2018) [Sustainability Report of the City of Bonn (2016-18)], https://www.bonn.de/themen-entdecken/umwelt-natur/nachhaltigkeitsbericht.php.

The city of Bonn has vastly extended its cycling path network in recent years. According to the city's indicators on Environmental Quality and Resource efficiency, the length of cycle paths in metres per metre of traffic routes (roads with a permitted speed exceeding 30 kilometres per hour, excluding motorways and expressways) has gone up from 1.13 in 2003 to 1.44 in 2018, particularly due to the development of its cycle route concept in 2012. In that framework, a total of 182 bicycle lanes and bicycle-road sections with a total length of approximately 52 kilometres have been planned in Bonn. To date, 58 cycle routes (sections) have already been built (Figure 2.8).

Despite the expansion of the cycle path network, the modal split has been stable over the past years with commuting by private car remaining the most popular option used by $29 \%$ of the city's population. Another $12 \%$ commute as additional passengers in private cars. Public transport is used by $17 \%$ while cycling and walking are respectively the preferred options for $15 \%$ and $28 \%$ of Bonn's inhabitants. This means that private transport is an option used less frequently in Bonn than in Germany overall. Accordingly, the shares of less pollutant public transport usage, as well as cycling and walking, are slightly higher than the country average. Overall, the modal split has been very stable over the past ten years, indicating only marginal changes in commuting modes. 
Figure 2.8. Length of cycle paths per metre of traffic routes in the city of Bonn

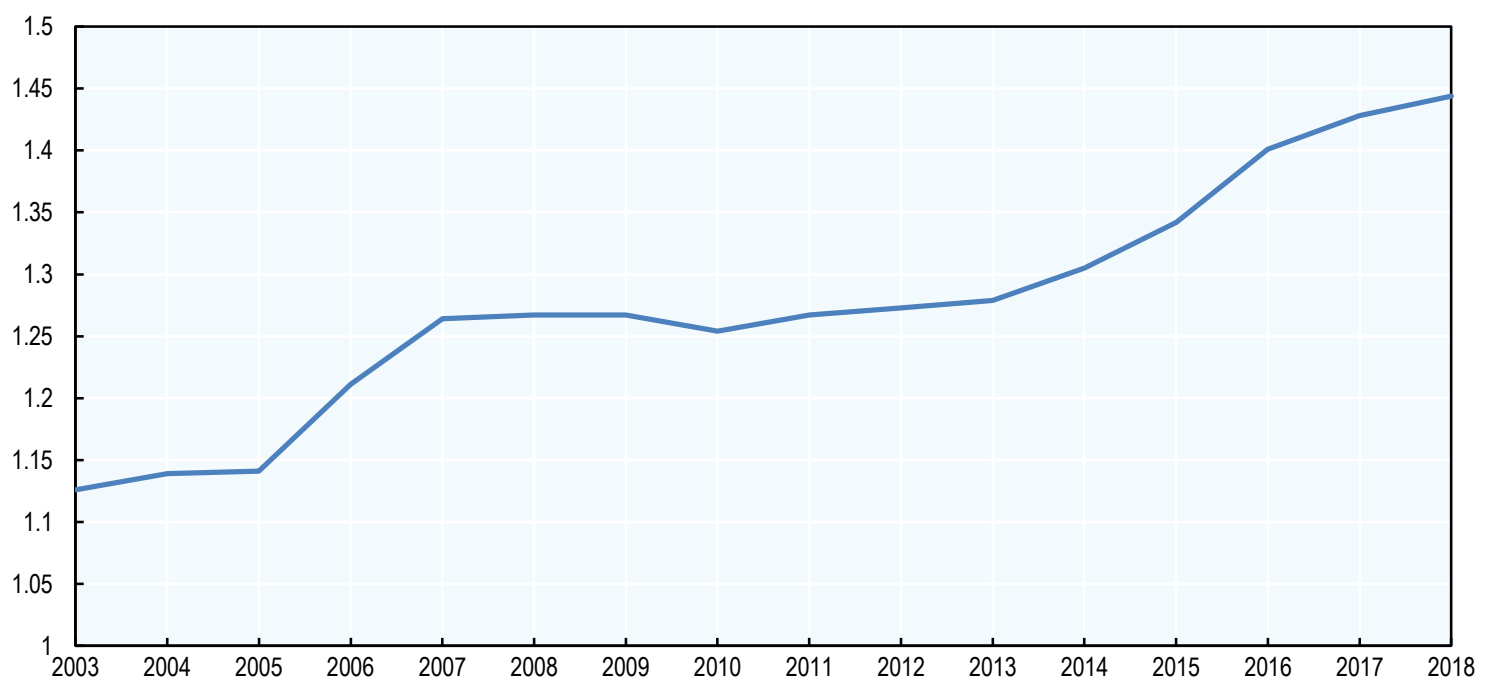

Note: Traffic routes are considered as roads with a permitted speed exceeding 30 kilometres per hour, excluding motorways and expressways. Source: City of Bonn (2019 $\left.9_{[1]}\right)$, Nachhaltigkeitsbericht der Stadt Bonn (2016-2018) [Sustainability Report of the City of Bonn (2016-18)], https://www.bonn.de/themen-entdecken/umwelt-natur/nachhaltigkeitsbericht.php.

\section{Dimension Prosperity: Good innovation and business creation but fossil fuels and public transport are challenges}

Spotlight on the OECD Localised Indicator Framework - FUA indicators

Table 2.5. OECD indicators used to assess the dimension Prosperity in the FUA of Bonn

\begin{tabular}{|c|c|}
\hline SDG & Indicator \\
\hline \multirow{4}{*}{ \% } & Percentage of total electricity production that comes from renewable sources \\
\hline & Percentage of total electricity production that comes from coal \\
\hline & Percentage of total electricity production that comes from fossil fuels (natural gas and oil, excluding coal) \\
\hline & Percentage of total electricity production that comes from nuclear power \\
\hline \multirow{3}{*}{ 价 } & Annual growth rate of real gross domestic product (GDP) per capita (\%) \\
\hline & Annual growth rate of real gross value added (GVA) per worker (\%) \\
\hline & Gender gap in the unemployment rate (percentage points) \\
\hline \multirow{3}{*}{3} & Performance of public transport network, ratio between accessibility and proximity to people \\
\hline & Performance of car transport network, ratio between accessibility and proximity to people \\
\hline & Patent applications (PCT) per 1000000 people \\
\hline \multirow{7}{*}{ A } & Performance of public transport network, ratio between accessibility and proximity to hospitals \\
\hline & Performance of car transport network, ratio between accessibility and proximity to hospitals \\
\hline & Difference between built-up area growth rate and population growth rate (percentage points) \\
\hline & Exposure to PM2.5 in $\mu \mathrm{g} / \mathrm{m}^{3}$, population-weighted (micrograms per cubic metre) \\
\hline & Percentage of people exposed to more than $10 \mu \mathrm{g} / \mathrm{m}^{3}$ (micrograms per cubic metre) of PM2.5 \\
\hline & Percentage of population with access to at least 1 hectare of green urban areas (parks) and forests within 15 minutes of walking \\
\hline & $\begin{array}{l}\text { Percentage of population with access to at least one recreational opportunity (theatres, museums, cinemas, stadiums or cultural } \\
\text { attractions) within } 15 \text { minutes of cycling }\end{array}$ \\
\hline
\end{tabular}

Source: OECD (2020[3]), A Territorial Approach to the Sustainable Development Goals: Synthesis Report, https://doi.org/10.1787/e86fa715-en, OECD (2020[5]), Measuring the Distance to the SDGs in Regions and Cities (visualisation tool), http://www.oecd-local-sdgs.org/ (accessed on 12 May 2020) 
More than one third of the electricity production of the FUA of Bonn comes from renewable resources but the FUA largely relies on fossil fuels to produce electricity. While Bonn does not use nuclear power or coal to generate electricity, more than $64 \%$ of its electricity production is based on fossil fuels such as natural gas and oil, which is almost twice as high as the FUA OECD average, but supposed to reach an end value $0 \%$ by 2030 (Figure 2.9). Accordingly, the FUA's share of electricity production from renewable sources of $36 \%$ is lower than the end value and needs to be increased by close to 45 percentage points in order to reach the end value by 2030. The FUA's achievements for SDG 7 Clean and Affordable Energy, therefore, leave some space for improvement. In contrast to the situation in the FUA, renewable energy is more prevalent in the city of Bonn. Following a positive growth trend since the early 2000 s, when renewable energy accounted for only $12.5 \%$ of energy in the electricity mix of the municipal energy provider Stadtwerke Bonn, its share reached $72.2 \%$ in 2018 exceeding both the state average of North RhineWestphalia (12.8\%) and the national average (37.8\%). During the period 2002-2018, the share of energy stemming from photovoltaics and solar thermal power in the city of Bonn's energy consumption increased from $0.02 \%$ to $0.12 \%$ for photovoltaics and $0.25 \%$ for solar thermal power.

Figure 2.9. Percentage of total electricity production that comes from fossil fuels - Natural gas and oil, excluding coal (2019): Comparison across FUAs

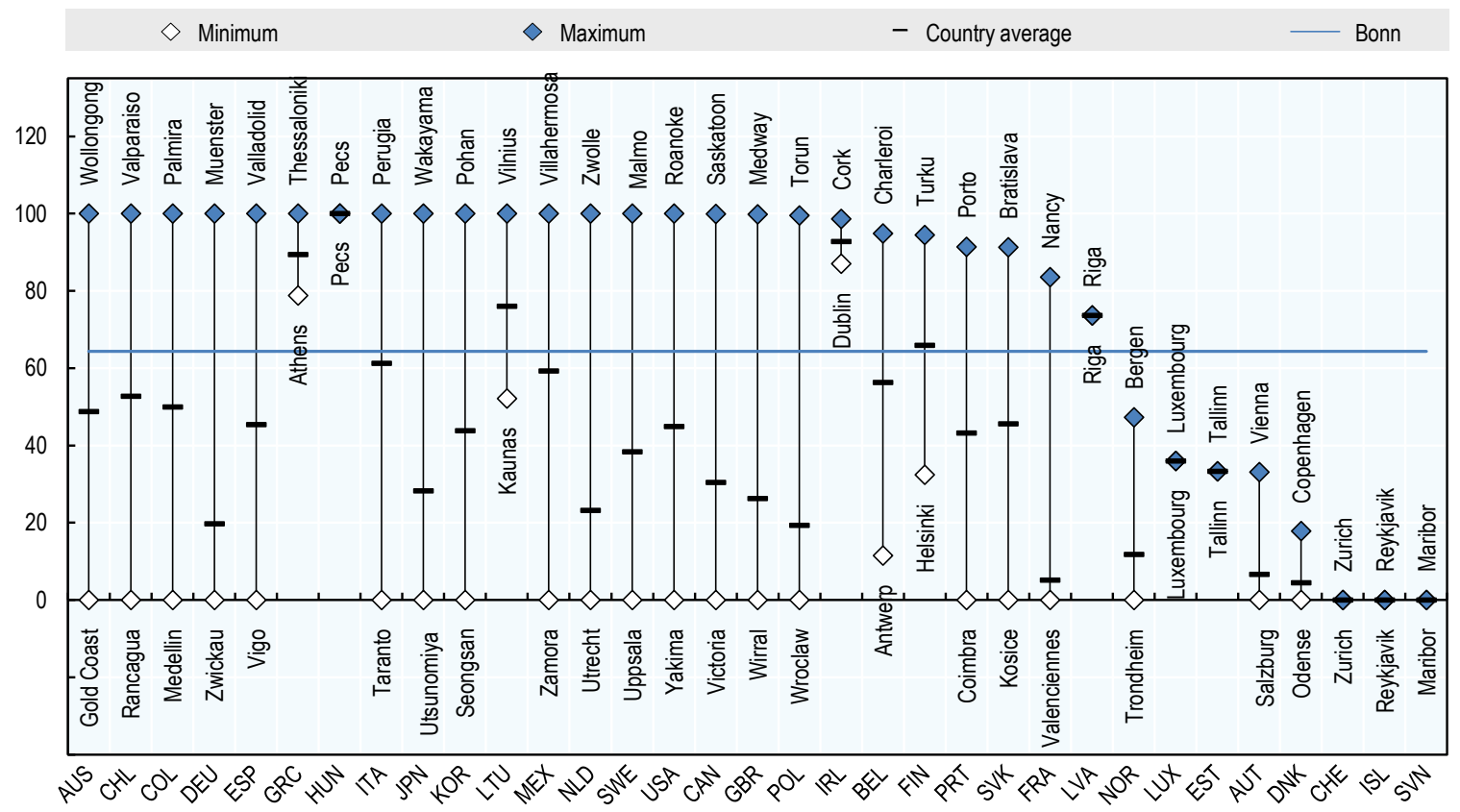

Source: OECD (2020[6]), OECD Regional Statistics (database), http://dx.doi.org/10.1787/region-data-en.

Decent work and economic growth are an area where the FUA Bonn shows mixed outcomes. Its growth rates of real GDP per capita and real GVA per worker in 2015, the latest year where comparable data for a sufficient number of OECD FUAs is available, were lower than the OECD average $(0.78 \%$ vs. $0.82 \%$ in the case of the GDP, $0.14 \%$ vs. $1.09 \%$ in the case of the GVA). They also remained below the end values that are slightly higher than $2 \%$ in both of the cases. In that context, the GDP per capita in the FUA of Bonn of 54948 USD (2018 value in constant prices, constant power purchasing parities, base year 2015) is already at a high level above the average of German FUAs (49 354 USD). On a positive note, the FUA of Bonn managed to close the gender gap in the unemployment rate. The gender gap is actually negative (1.43 percentage points), which means that more men than women are unemployed. 
Using the number of patents to measure the level of innovation, the FUA of Bonn is performing well. In 2014, the latest year where comparable data was available, the FUA of Bonn registered 654 patents per 1000000 people, which can be used as an indicator to appraise the FUA's achievements in SDG 9 Industry, Innovation and Infrastructure. Overall, in the FUA of Bonn, there were more than twice as many patent applications as in the average OECD FUA. Despite having a gap of more than 100 patent registrations to bridge to reach the end value of 779 , Bonn's FUA is ahead of close to $90 \%$ of OECD FUAs in this indicator.

In the FUA of Bonn, connectivity is higher by car than public transport, relative to other OECD FUAs. Transport performance is one indicator to measure SDG 9 Industry, Innovation and Infrastructure. It compares the total number of destinations accessible (by car, public transport or bicycle) with the number of destinations nearby (within a set radius). Transport performance is computed as the ratio between the absolute accessibility for a given mode and proximity to potential destinations. A ratio of one or more means the mode performs well, a ratio close to zero means the mode performs poorly, even in providing access to nearby destinations. While in most OECD FUAs, car transport performance is higher than the one of public transport, this difference is more pronounced in the FUA of Bonn than in other OECD FUAs. The ratio of the FUA of Bonn's public transport network between accessibility and proximity of its people is 0.29 , which is only slightly more than half as high as the end value and lower than the OECD FUA average of 0.38 . In the case of its car transport network, its value of 2.53 exceeds the OECD average and the relative distance to the end value of 2.75 is smaller. Improving public transport performance can be an important contributory factor to create more sustainable cities through the reduction of the number of fossilfuel consuming private vehicles. The same pattern of a better relative performance of the car transport network compared to the public transport network can also be observed in the case of the ratio between accessibility and proximity to hospitals where the public transport network performance ratio of 0.36 is below the OECD FUA average of 0.42 and the end value 0.58 , while the car transport network performance ratio of 3.00 exceeds both the average and the end value. When looking at the city of Bonn itself, $87.5 \%$ of the residents live within a radius of less than 300 metres (as the crow flies) from a train station, bus or tram stop that is served between Monday and Friday from 7:00 to 12:00 and from 14:00 to 19:30 at least every 15 minutes.

The FUA of Bonn's indicators for SDG 11 Sustainable Cities and Communities exhibit results mostly around or below the OECD FUA average. In terms of air pollution, for instance, the FUA of Bonn registered an average exposure to $\mathrm{PM} 2.5 \mathrm{in} \mu \mathrm{g} / \mathrm{m}^{3}$ (population-weighted - micrograms per cubic metre) of 11.5 , which is slightly lower than the OECD FUA average of $12.7 \mu \mathrm{g} / \mathrm{m}^{3}$ but higher than the level recommended by the World Health Organization (WHO) (of 10 micrograms per cubic metre). Around $50 \%$ of OECD FUAs expose their communities to a lower degree of PM 2.5. In addition, a small gap remains to the end value of below $10 \mu \mathrm{g} / \mathrm{m}^{3}$. Overall, around $87 \%$ of the FUA of Bonn's population is exposed to more than $10 \mu \mathrm{g} / \mathrm{m}^{3}$. The majority of OECD FUAs registered a smaller share of its population - on average around $60 \%$ exposed to such PM 2.5 levels. In addition, Bonn's FUA is far from achieving the end value of $0 \%$ of the population exposed to more than $10 \mu \mathrm{g} / \mathrm{m}^{3}$ of PM 2.5 in 2030.

Despite high levels of air pollution, the FUA of Bonn offers high proximity to green spaces. A total of $99 \%$ of the population has access to at least 1 hectare of green urban areas (parks) and forests within 15 minutes of walking. It thus already reaches the end value for 2030 set at $96.6 \%$ for that specific indicator. 
Spotlight on administrative indicators collected by the city of Bonn

Table 2.6. Selected Bonn-specific administrative indicators used to assess the dimension Prosperity

\begin{tabular}{|c|c|c|}
\hline SDG & Indicator & Definition \\
\hline 7. $11=13=$ & Renewable energy & Share of renewable energy in the electricity mix of Stadtwerke Bonn \\
\hline 7. $11=13$ & $\begin{array}{l}\text { Renewable energy - Solar } \\
\text { energy production }\end{array}$ & $\begin{array}{l}\text { Energy production of photovoltaic and solar thermal systems in urban areas as a } \\
\text { percentage of total energy consumption }\end{array}$ \\
\hline 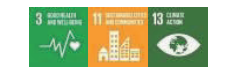 & Air quality & $\begin{array}{l}\text { Air pollutant concentrations: Nitrogen dioxide, particulate matter PM 10, benzene: } \\
\text { Annual average value as a percentage of the threshold value }\end{array}$ \\
\hline 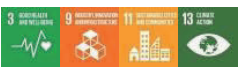 & Access to public transport & $\begin{array}{l}\text { Percentage of inhabitants living within a radius of less than } 300 \mathrm{~m} \text { (as the crow flies) } \\
\text { from a stop that is served }\end{array}$ \\
\hline 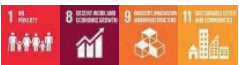 & Business start-ups & Number of newly registered businesses per 100 de-registered businesses \\
\hline TI $00^{13}$ & Eco-certified companies & $\begin{array}{l}\text { Number of Eco-Management and Audit Scheme (EMAS) and ÖKOPROFIT certified } \\
\text { companies per } 1000 \text { registered companies }\end{array}$ \\
\hline LII TI & Innovative strength & $\begin{array}{l}\text { Percentage of employees in knowledge-based services out of all employees subject to } \\
\text { social insurance contributions at the place of work }\end{array}$ \\
\hline
\end{tabular}

Source: City of Bonn (2019 $\left.{ }_{[1]}\right)$, Nachhaltigkeitsbericht der Stadt Bonn (2016-2018) [Sustainability Report of the City of Bonn (2016-18)], https://www.bonn.de/themen-entdecken/umwelt-natur/nachhaltigkeitsbericht.php.

PM 10 and Benzene levels in the city of Bonn comply with European norms, while NO2 levels exceed the EU air quality standard ${ }^{4}$. In 2018, the average annual concentration of PM 10 reached $100 \%$ of the threshold value recommended by the European Commission (average annual exposure of $40 \mu \mathrm{g} / \mathrm{m} 3$ ), however exceeded the air quality guidelines of the WHO $\left(20 \mathrm{\mu g} / \mathrm{m}^{3}\right.$ annual mean). The Benzene levels also stayed within the EU norm reaching $70 \%$ of the EU air quality standard threshold. In terms of concentration of $\mathrm{NO}_{2}$ the city of Bonn exceeded the EU air quality standard by $25 \%$. Overall, the level of air pollution in the city of Bonn has nevertheless been following a downward trend in the last years.

The city of Bonn experienced a net growth in the number of companies registered in the city over the past years. Between 2009 and 2018, on average 110 businesses were newly registered per 100 de-registered companies (Figure 2.10). However, the rate has been following a downward trend since 2004 falling to a rate of 100.2 in 2018. The average net business creation rate in the state of North Rhine-Westphalia shows a similar trend. 
Figure 2.10. Number of newly registered businesses per 100 de-registered businesses in the city of Bonn

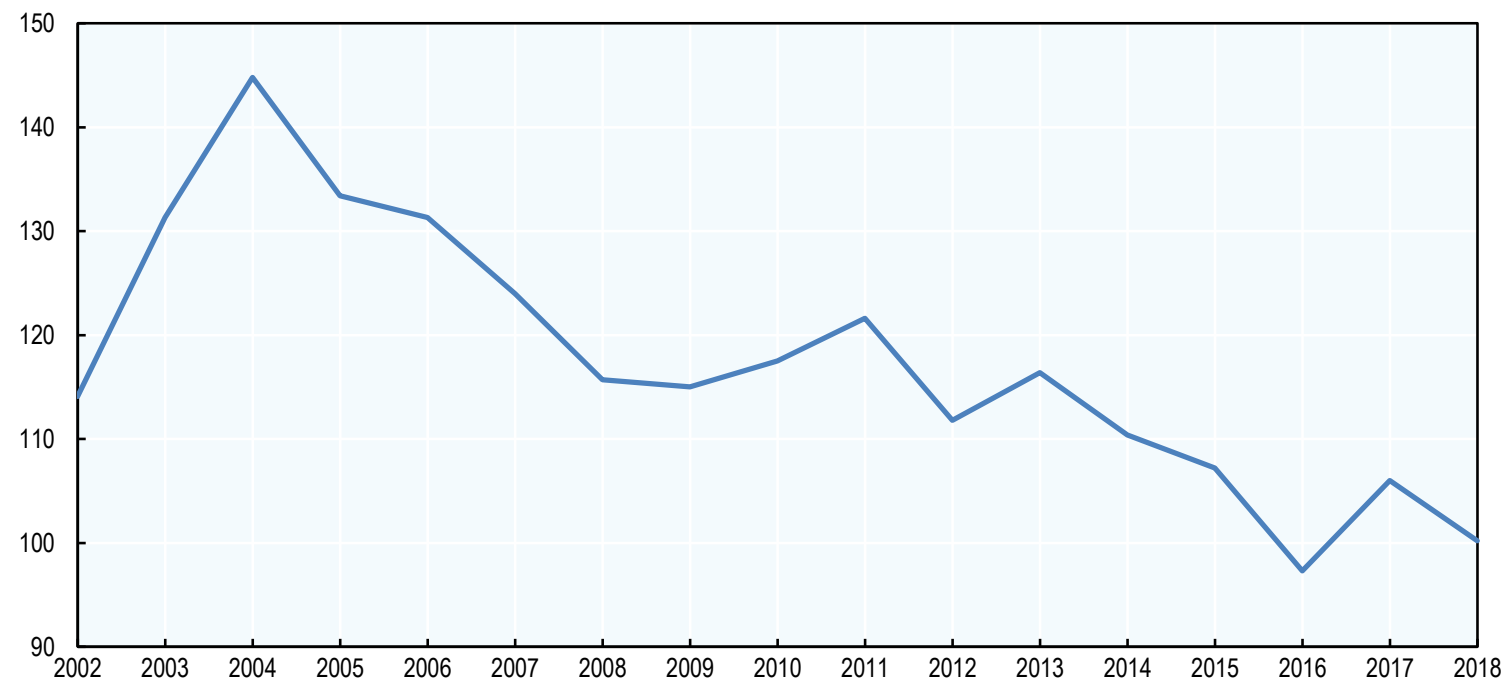

Source: City of Bonn (2019 $\left.{ }_{[1]}\right)$, Nachhaltigkeitsbericht der Stadt Bonn (2016-2018) [Sustainability Report of the City of Bonn (2016-18)], https://www.bonn.de/themen-entdecken/umwelt-natur/nachhaltigkeitsbericht.php.

The number of eco-certified companies in the city of Bonn is still marginal but on the rise. As of 2017, there were 1.09 Eco-Management and Audit Scheme (EMAS) and ECOPROFIT5 certified companies per 1000 registered companies following an upward trend over the past 3 years. Those could act as role models on a pathway towards the implementation of more sustainable business models.

Knowledge-based services are an important driver of the city's economy. A total of $38.4 \%$ of employees subject to social insurance contributions are working in knowledge-based services following an overall growth rate of 1.4 percentage points between 2012 and 2018. This provides Bonn with good prerequisites to boost knowledge-intensive innovations and increase the competitiveness of the local economy.

\section{Dimensions Peace and Partnership: Citizen participation and the commitment to international co-operation are strong assets}

Spotlight on the OECD Localised Indicator Framework - FUA indicators

Table 2.7. OECD indicators used to assess the dimensions Peace and Partnership in the FUA of Bonn

\begin{tabular}{c|c}
\hline SDG & Indicator \\
\hline \begin{tabular}{c|c}
\hline 1 \\
\hline
\end{tabular} & Percentage of houses and buildings connected to optical fibre networks \\
\hline
\end{tabular}

Source: OECD (2020[3]), A Territorial Approach to the Sustainable Development Goals: Synthesis Report, https://doi.org/10.1787/e86fa715-en, OECD (2020[5]), Measuring the Distance to the SDGs in Regions and Cities (visualisation tool), http://www.oecd-local-sdgs.org/ (accessed on 12 May 2020)

The FUA of Bonn is characterised by low coverage of houses and buildings connected to optical fibre networks. In 2017, only $3 \%$ of houses and buildings in the FUA of Bonn were connected to optical fibre networks. Its FUA is hence lagging behind a vast majority of OECD FUAs, whose average connectivity to optical fibre networks is close to $20 \%$. The distance to the end value that the FUA of Bonn still has to bridge 
until 2030 is even larger. More than an additional $50 \%$ of houses and buildings in the FUA would need to be connected to optical fibre networks to reach the end value of $59 \%$ (Figure 2.11). The share of households connected to broadband internet through optical fibre in the city of Bonn itself $(6 \%)$ is slightly higher than in the FUA overall, but also remains below the end value. Reaching the end value for this indicator is of particular relevance in the current context of the Covid-19 pandemic as it provides employees in various sectors the opportunity for remote work options.

Figure 2.11. Percentage of houses and buildings connected to optical fibre networks (2017): Comparison across FUAs

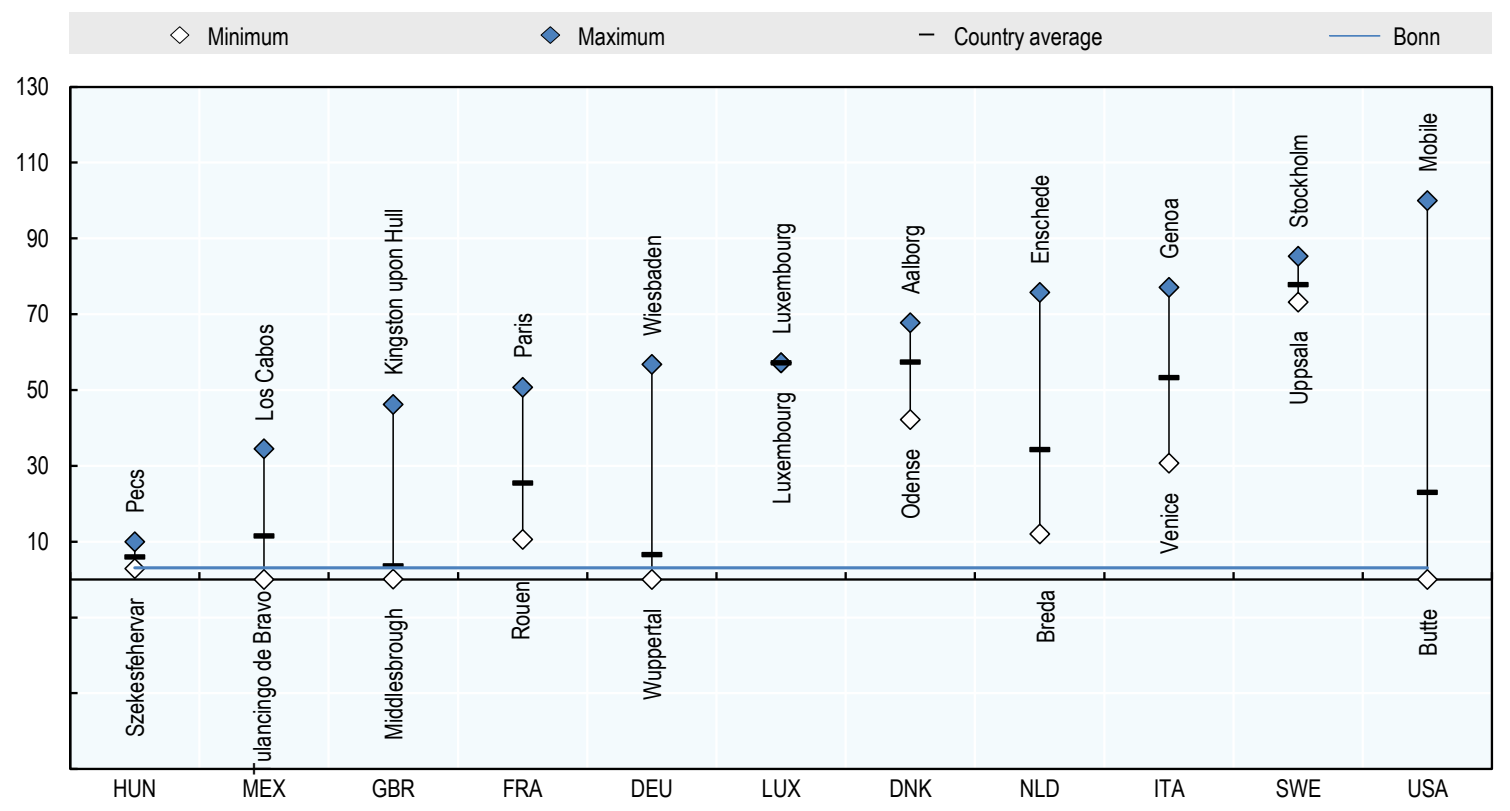

Source: OECD (2020[6]), OECD Regional Statistics (database), http://dx.doi.org/10.1787/region-data-en.

Spotlight on administrative indicators collected by the city of Bonn

Table 2.8. Selected Bonn-specific administrative indicators used to assess the dimensions Peace and Partnership

\begin{tabular}{c|l|l}
\hline \multicolumn{1}{c|}{ SDG } & \multicolumn{1}{c|}{ Indicator } & \multicolumn{1}{c}{ Definition } \\
\hline & Associations & Number of associations per 1000 inhabitants \\
\hline & Informal citizen participation & Number of informal civic participation procedures \\
\hline & Number of offences recorded & Number of offences recorded per 1000 inhabitants \\
\hline & $\begin{array}{l}\text { Violent crimes, street crimes, } \\
\text { property offences }\end{array}$ & $\begin{array}{l}\text { Number of recorded offences per } 1000 \text { inhabitants in the areas of violent } \\
\text { crime, street crime and property offences }\end{array}$ \\
\hline & Broadband coverage & $\begin{array}{l}\text { Proportion of households with broadband access } \geq 50 \text { mbit/s by optical } \\
\text { fibre }\end{array}$ \\
\hline
\end{tabular}

Source: City of Bonn (2019[1]), Nachhaltigkeitsbericht der Stadt Bonn (2016-2018) [Sustainability Report of the City of Bonn (2016-18)], https://www.bonn.de/themen-entdecken/umwelt-natur/nachhaltigkeitsbericht.php. 
There is a lack of comparable data for the FUA of Bonn for SDG 16 Peace, Justice and Institutions. The city of Bonn, however, is collecting some indicators that fall into the scope of the SDG but are not part of the OECD localised indicator framework, for instance the number of criminal offences recorded per 1000 inhabitants. In 2018, the value for the city of Bonn in this indicator reached 85 compared to the national country average of 68 . However, one can identify a positive trend as the crime rate has been declining since 2015 and is now well below the average value for the period between 2006 and 2018 (109 offences per 1000 inhabitants) (Figure 2.12). The decrease can mainly be explained by a decline in property offences (40.6 per 1000 inhabitants in 2018 compared to 57.3 in 2015) and street crime cases (24.0 per inhabitant compared to 33.0 in 2015).

Figure 2.12. Number of criminal offences recorded per 1000 inhabitants (2018) in the city of Bonn

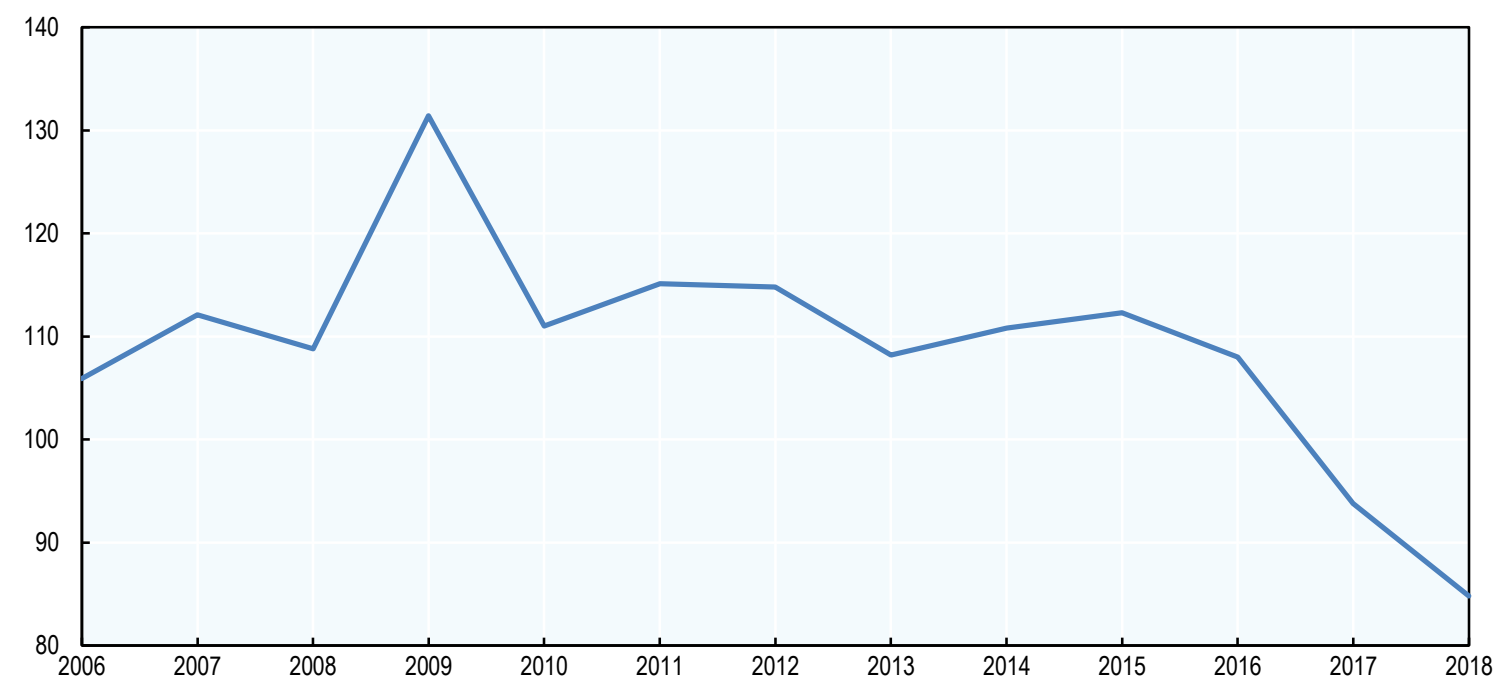

Source: City of Bonn (2019[1]), Nachhaltigkeitsbericht der Stadt Bonn (2016-2018) [Sustainability Report of the City of Bonn (2016-18)], https://www.bonn.de/themen-entdecken/umwelt-natur/nachhaltigkeitsbericht.php.

Civic participation procedures and engagement are on the rise in the city of Bonn. In 2018, 33 informal civic participation procedures that involve citizens in the design of municipal strategies were applied in Bonn, up from 18 in 2016. Another indicator the city of Bonn is using to measure SDG 16 Peace, Justice and Institutions is the number of associations per 1000 inhabitants. In 2018, there were 13.2 associations and clubs per 1000 inhabitants registered in the city. That means that there are close to twice as many associations in Bonn as in Germany on average (7.6 in 2014), indicating a strong sense of community.

The city of Bonn is steadily increasing its One World Commitment. The city of Bonn is measuring SDG 17 through its municipal One World Commitment, which encompasses municipal expenditure on development co-operation and funds for partnerships and projects with local authorities in developing countries and countries in Eastern Europe ${ }^{6}$. The city of Bonn calculates these expenditures per 1000 inhabitants. Its municipal expenditure on One World Commitment and Fair Trade products has steadily been increasing in the past years. It went up from around EUR 300 per 1000 inhabitants in 2015 to more than EUR 600 per 1000 inhabitants in 2018. 


\section{The SDGs: A means to link environmental, economic and social performance in Bonn, Germany}

The city of Bonn identifies SDG 11 Sustainable Cities and Communities as an ambitious framework to drive the city's well-being. With a growing population, demand for housing, energy and transport is adding pressure to Bonn's urban development. SDG 11 is therefore seen as particularly relevant for generating synergies with SDG 7 (Clean and Affordable Energy), SDG 12 (Responsible Production and Consumption) and SDG 13 (Combating Climate Change). The population of Bonn is growing very fast. Between 2011 and 2018, the population of the FUA of Bonn has increased by $4.7 \%$ from around 883000 to 925000 residents representing a considerable increase compared to the average of German FUAs, which amounts to $3.4 \%$ over the same period. Taking into account only the population increase within administrative boundaries of the city of Bonn, the population growth rate was $5.4 \%$, which is displayed in an increase from roughly 313000 to more than 330000 residents in the same period (Figure 2.13), underlining an even higher relative population increase in the core area. Moreover, the built-up area in the FUA of Bonn is growing faster than the population size, which poses additional challenges in terms of accessibility and reducing transport-related emissions.

Figure 2.13. Demographic dynamics in the city of Bonn and its functional urban area, 2011-18

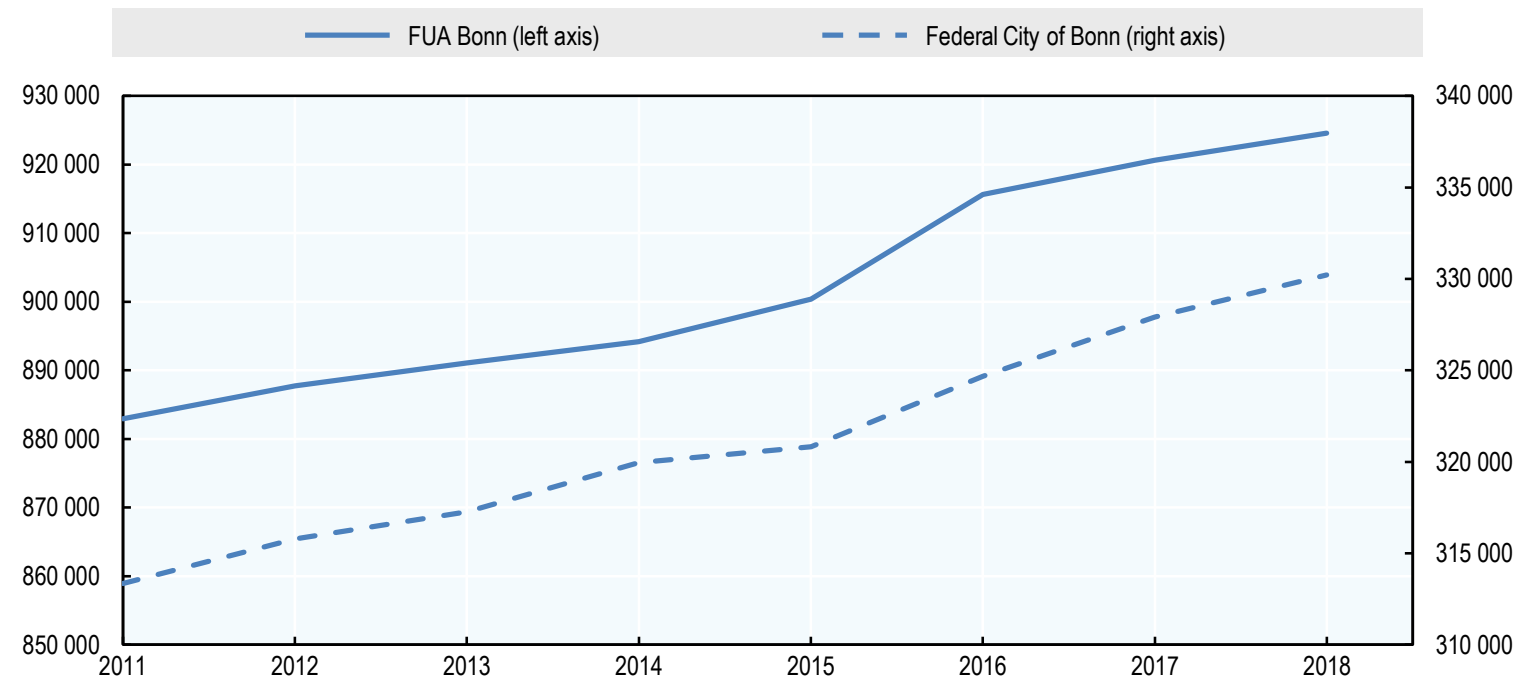

Source: OECD (2020[7]), Regions and Cities - Metropolitan Areas (database), https://stats.oecd.org/ (accessed on 14 March 2020).

Reducing air pollution, providing clean and affordable energy, and transitioning towards low-carbon means of transport will be key to build a sustainable city but require managing several trade-offs. For instance, mitigation and adaptation to climate change (SDG 13) through the reduction of greenhouse gas (GHG) emissions will imply maintaining and developing green spaces (SDG 11 or 15) while continuing to provide sufficient housing quality and quantity. It will also require reducing private transportation in favour of public transport while responding to the needs of a growing and elderly population in terms of transport. It will also mean transitioning towards more efficient and greener, and often more costly, energy sources, promoting sustainable production (SDG 12) while ensuring that vulnerable groups have access to affordable electricity and products. The SDGs provide a framework to analyse these types of interlinkages and manage the trade-off between key policy areas for the sustainability of the FUA and city of Bonn, in particular: climate and air quality, transport and sustainable mobility, business development, clean energy, affordable housing and old-age poverty. 
The consequences of climate change in Bonn led the city to issue a Climate Emergency. In July 2019, Bonn's city council declared a climate emergency initiated by a citizen proposal. In a high-level political statement by the mayor 150 measures to tackle climate change were proposed around six categories (solar energy, climate-friendly building and living, sustainable city, urban development, campaigns and communication, and climate adaptation). The final objective, adopted by the council in November 2019, is that Bonn becomes a climate neutral city by 2035 (City of Bonn, 2019 ${ }_{[8]}$ ).

The climate emergency in the city of Bonn should accelerate efforts to tackle SDG 13 Climate Action. In particular, the city will have to place strong efforts in reducing emissions to become climate neutral by 2035. In view of its $\mathrm{CO}_{2}$ emission levels, the FUA of Bonn would need to pursue an ambitious programme to cut emissions from electricity production by almost two-thirds to reach the end value by 2030 . A further expansion of the tree cover, for instance by greening roofs could contribute to extend carbon storage possibilities.

Improving the transport system is key to achieve climate neutrality by 2035 . Clean air and reduced $\mathrm{CO}_{2}$ emissions are high on the political agenda in the city of Bonn and, as for several other German cities, reducing $\mathrm{NO}_{2}$ levels to meet European norms is challenging because of a growing population and persistently high rates of individual motorised vehicle traffic in the city, due to - among other things - high commuting flows. Mobility is thus an important issue in the public debate, both from a health hazard and a social standpoint. As commuting by private car currently remains the most popular option for people living in the city of Bonn, further efforts to improve the attractiveness of public transport will be necessary. In addition, the city of Bonn will need to increase the efforts in the expansion of cycling lanes to incentivise its residents to switch to more environmentally friendly means of transport. In the city of Bonn's policy strategies, the promotion of cycling has already gained some traction through the development of the Bonn cycle route concept in 2012. Planned investments in these areas also offer the opportunity to improve the overall transport system in Bonn.

The creation of "green" businesses could help to connect the environmental and economic dimensions of sustainability. Start-ups and young companies are a focus of the municipal economic development department, as they allow to generate an important contribution to local economic development. They can further stimulate the economic structural change of the city by fostering innovation, creating sustainable jobs and revitalising entrepreneurship (City of Bonn, 2019[1] $)$. The creation of sustainable businesses can play a key role in the context of decreasing growth rates in the net creation rate of firms in the city of Bonn over the past years. Building on the existing EMAS and ECOPROFIT certified companies in the city of Bonn and its innovative strength displayed in its high number of patent registrations, the city could further develop or adapt existing strategies and schemes to also support young companies that meet sustainability standards and encourage existing SMEs to apply sustainable business models in order to connect the environment and the economic dimension of sustainability.

The transition towards low-carbon transport and energy could have a distributional impact on people's disposable income and may require compensatory measures. On the one hand, energy efficiency can generate cost savings and thus have positive effects on low-income populations. On the other hand, climate policies to mitigate air pollution can also have a regressive impact and risk to disproportionately affect low-income households (Mclnnes, 2017[9]). This is particularly relevant for Bonn, where environmental goals are a strong focus of the city's public policy and the issue of mobility is already generating a lively public debate at the local level. A population group that should be carefully considered when implementing these policies are the elderly since old-age poverty is an increasing challenge for the city of Bonn. In view of the demographic change and a larger share of the elderly population (from $16.5 \%$ to $18.0 \%$ of the total population between 2002 and 2012), notably the increasing share of recipients of basic income support aged above 65 , old-age poverty is becoming one of the crucial social policy issues in the city of Bonn. In addition, the city should equally consider the impact of climate measures on the youth as they are another category at risk of poverty. 
Reducing the number of children and youth living in poverty is vital to enable more equal opportunities across society. The reasons for child and youth poverty can be manifold ranging from parental unemployment, single-parent households, low wages for the low-skilled workforce or a large number of children. In the city of Bonn, the number of young people under 18 living in households eligible for transfer payments has increased by around 5.3\% from an average of 11079 in 2016 to an average of 11671 in 2018 (City of Bonn, 2019 ${ }_{[1]}$ ). In order to allow those disadvantaged groups to rely less on state transfer payments in the future, it is important to ensure equal opportunities. In addition to securing basic needs and accommodation, the city of Bonn is, therefore, putting a main focus on ensuring equal opportunities in education systems, for instance (City of Bonn, 2019 $9_{[1]}$ ).

Ensuring access to affordable housing in the city of Bonn requires taking into account several parameters such as old-age poverty, building permits and the increase of rents in the city. Bonn is a dynamically growing city in an attractive location within North Rhine-Westphalia. On the one hand, population growth and, at the same time, demographic change and declining income for the elderly are increasing the number of households entitled to social housing. On the other hand, the difficulties to conduct new housing developments due to the decrease in the number of building permits limit the housing offer (City of Bonn, $\left.2019_{[1]}\right)$ ). In addition, the average rent in the city of Bonn has increased by $14 \%$ between 2014 and 2018 making Bonn the $4^{\text {th }}$ most expensive rental market in the state of North Rhine-Westphalia. Housing prices have increased by more than $30 \%$ in the same period and in particular in the lower segments (LEG, $\left.2019_{[10]}\right)$. Access to affordable housing is, therefore, gaining particular traction in policy debates. Affordable housing is also crucial for the unemployed and the low-skilled labour force. The employment structure in the city of Bonn shows a very large degree of tertiarisation (92\%) and a high level of required knowledge and skills. The employment share at the low-skilled level on the other hand only accounts for $10 \%$ of total employment. Consequently, there are eight unemployed persons for every registered job in low-skilled sector pointing out the lack of job opportunities for the low-skilled labour force. Moreover, in recent years, the availability of subsidised housing is decreasing in relative terms to the increase of entitled households. In view of a possible stressed housing market, the city of Bonn passed a resolution to introduce the Bonn Building Land Model in 2017. The objective was to create more affordable housing throughout the city and to share the costs of social infrastructure with real estate developers. The model provides uniform and binding regulations for all housing development projects. It establishes that developers commit through an urban development contract to construct $40 \%$ of the gross floor area of a new building project planned for residential purposes under the conditions of subsidised housing and to cover a share of the costs for the development of childcare institutions in day care centres (City of Bonn, 2019 ${ }_{[1]}$ ).

The city of Bonn could also use the SDGs to embrace a functional approach at the metropolitan level to enhance sustainable urban development challenges at the appropriate scale. For instance, a clear example are transport policies. The built-up area per capita in the periphery is 2.3 times higher than in the core (administrative city of Bonn), thus leading to pronounced urban sprawl. The latter implies that strong co-ordination in public transport policies could help mitigate an increase in private car utilisation, thus achieving other critical objectives of the city such as climate mitigation or sustainable production. In practice, this means that many policies underlying the city Bonn's Sustainability Strategy should be based on where people work and live and the economic geography of the city, rather than mere administrative boundaries. This also means that the SDGs can provide a common framework that neighbouring municipalities can use to strengthen collaborations and to co-ordinate actions across Bonn's urban core and the periphery, and between rural and urban territories. 


\section{References}

City of Bonn (2019), Nachhaltigkeitsbericht der Stadt Bonn (2016-2018) [Sustainability Report of the City of Bonn (2016-18)], https://www.bonn.de/themen-entdecken/umwelt-

natur/nachhaltigkeitsbericht.php.

City of Bonn (2019), Nachhaltigkeitsbericht der Stadt Bonn (2016-2018) [Sustainability Report of the City of Bonn (2016-2018)].

City of Bonn (2019), "Rat beschließt: Bonn soll bis 2035 klimaneutral werden [Council decides: Bonn to become climate neutral by 2035]", https://www.bonn.de/pressemitteilungen/2019/november/rat-beschliesst-bonn-soll-bis-2035klimaneutral-werden.php.

City of Bonn (2019), Rat beschließt: Bonn soll bis 2035 klimaneutral werden [Council decides: Bonn to become climate neutral by 2035], https://www.bonn.de/pressemitteilungen/2019/november/rat-beschliesst-bonn-soll-bis-2035klimaneutral-werden.php.

LEG (2019), LEG-Wohnungsmarktreport NRW 2019 [LEG Housing Market Report NRW 2019], https://www.legwohnen.de/fileadmin/user upload/Assets/PDFs/Unternehmen/Presse/Wohnungsmarktreporte Wohnungsmarktreport 2019/AQkVHgwgCH4/2019-09-26 Presseinfo LEGWohnungsmarktreport Bonn 2019.pdf.

McInnes, G. (2017), Understanding the Distributional and Household Effects of the Low-carbon Transition in G20 Countries, http://www.oecd.org/environment/cc/g20climate/collapsecontents/McInnesdistributional-and-household-effects-low-carbontransition.pdf.

OECD (2020), A Territorial Approach to the Sustainable Development Goals: Synthesis report, OECD Urban Policy Reviews, OECD Publishing, Paris, https://dx.doi.org/10.1787/e86fa715-en.

OECD (2020), Measuring the Distance to the SDGs in Regions and Cities (visualisation tool), OECD, Paris, http://www.oecd-local-sdgs.org.

OECD (2020), OECD Regional Statistics (database), OECD, Paris, http://dx.doi.org/10.1787/region-data-en.

OECD (2020), Regions and Cities - Metropolitan Areas (database), OECD, Paris, https://stats.oecd.org/ (accessed on 14 March 2020).

OECD (2019), Functional Urban Areas - Germany, OECD, Paris, https://www.oecd.org/cfe/regional-policy/Germany.pdf.

UN Sustainable Development Knowledge Platform (2020), Sustainable Development Goals, United Nations, https://sustainabledevelopment.un.org/?menu=1300. 


\section{Notes}

${ }^{1}$ While a total of 135 indicators are available for the measurement of the SDGs in both regions and cities in OECD countries, the coverage varies depending on the type of geographical unit to which each indicator is associated. While 122 indicators (covering 59\% of the subnational SDG targets) are available for regions, only 56 indicators (covering $32 \%$ of the SDG Subnational Targets) are currently available for cities. Although the set of indicators aims to cover the broad spectrum of all 17 SDGs, the coverage in terms of indicators also varies widely across SDGs. As a consequence, data for Bonn only covers 14 out of the 17 SDGs.

2 Terrestrial protected areas are totally or partially protected areas of at least 1000 hectares that are designated by national authorities as scientific reserves with limited public access, national parks, natural monuments, nature reserves or wildlife sanctuaries, protected landscapes and areas managed mainly for sustainable use.

${ }^{3}$ Municipal waste is mainly produced by households, similar waste from sources such as commerce, offices and public institutions are included. The amount of municipal waste generated consists of waste collected by or on behalf of municipal authorities and disposed of through the waste management system.

${ }^{4}$ While as of now, no measurements of PM 2.5 air pollution that would be comparable with the OECD localised indicator framework on the SDGs is undertaken in Bonn, the city measures the population's exposure to coarse particular matter PM 10, another common proxy indicator for air pollution looking at particles with a diameter of 10 microns or less, which can penetrate and lodge deep inside the lungs. The city of Bonn also measures $\mathrm{NO}_{2}$ and Benzene levels.

${ }^{5}$ ECOPROFIT is a co-operative approach between the regional authority and local companies with the goal of reducing cost for waste, raw materials, water and energy. Reductions in these areas also reduce environmental aspects of businesses.

${ }^{6}$ Municipal expenditure on development co-operation may include municipal grants for local refugee organisations, permanent rent subsidies from the municipality for One World shops and municipal grants for projects in these countries, such as co-financing a hospital in a partner city. It also includes financial support from the municipality for development policy events and public relations work such as brochures or exhibitions. Membership fees for associations such as Climate Alliance and expenditure on Fair Trade products (tea, coffee, chocolate) do also count as municipal expenditure on development co-operation as defined by the city of Bonn (City of Bonn, 2019 $\left.{ }_{[1]}\right)$. 



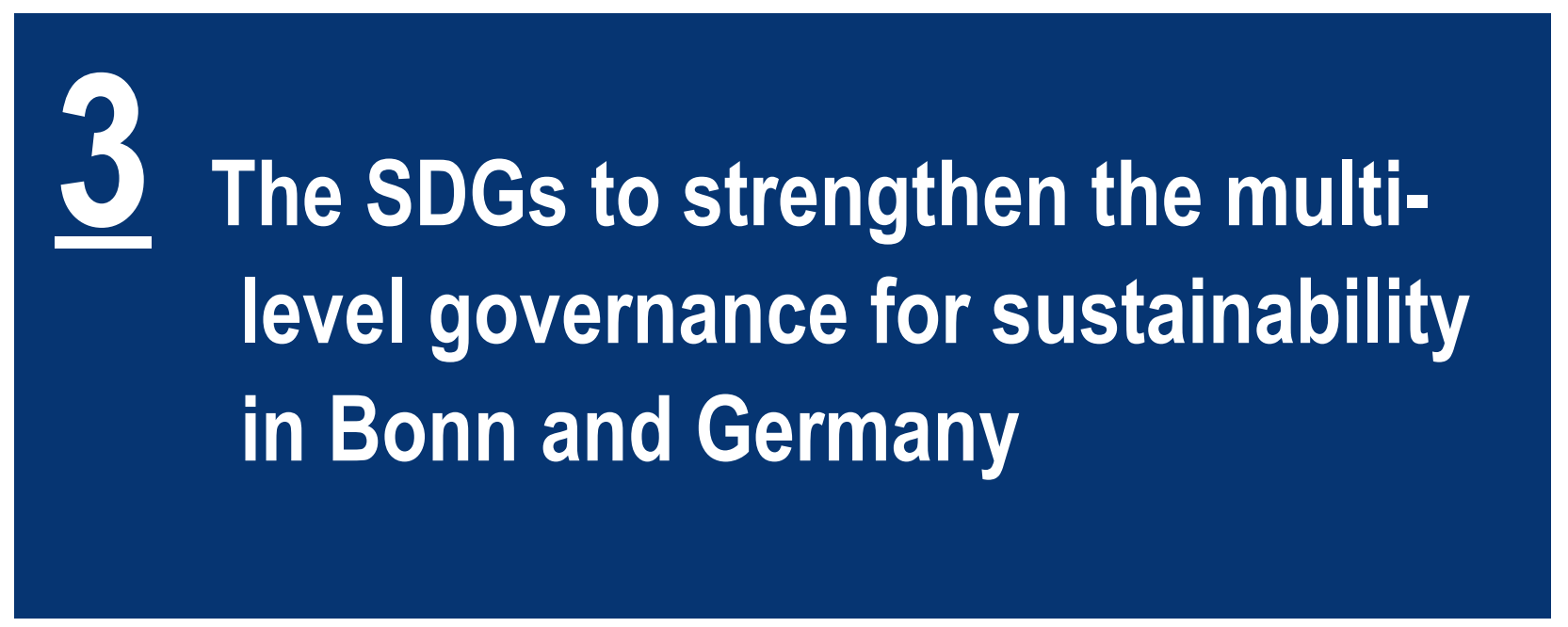

The SDGs represent a key opportunity to move forward the implementation of the Sustainability Strategy by strengthening the multi-level governance of sustainability, further engage the business community and raise awareness of the measures of the strategy to involve the civil society in its implementation. While sustainability strategies and policy priorities are well aligned across federal, state and local governments in Germany, co-ordinating the reporting on SDGs progress remains a challenge. In terms of stakeholder engagement, Bonn's many efforts have contributed to raising civil society's awareness of the 2030 Agenda, using the SDGs as an effective communication tool through communications and an engagement campaign. Nevertheless, private sector engagement can still be substantially strengthened in Bonn's Sustainability Strategy. 


\section{A solid multi-level governance framework that builds on sustainability and climate commitment}

\section{Strategic alignment across federal, Länder and local governments}

In the multi-level governance context of Germany, Länder and local governments ${ }^{1}$ are key when it comes to translating broad policy priorities into local action and have important powers to enact and enforce legislation relevant to sustainable development, including in mobility, energy and housing. The federal government's sustainability strategy therefore explicitly points to the importance of Länder and local governments in the implementation of the 2030 Agenda, acknowledging that "the Länder should be able to set their own priorities in the interest of federalism" (The Federal Government, 2016[1]), p. 46). At the same time, the diversity of approaches applied across the Länder is highlighted as a challenge that calls for alignment between subnational government strategies and the federal government's strategy.

In this context, the Sustainability Strategy of the city of Bonn aligns with both the federal government and North Rhine-Westphalia (NRW) strategies. For example, the incorporation of the SDGs into the federal government's revision of the German Sustainable Development Strategy in 2016 (the most significant revision since 2002) led to a more holistic approach to sustainable development. Most importantly, it enhanced the focus on the social dimension and global responsibility, including through 13 new topics and 30 indicators focused around fighting poverty, promoting equality, distributive justice, education, health, anti-corruption and healthy government finances (The Federal Government, $\left.2016_{[1]}\right)^{2}$ In the case of Bonn's Sustainability Strategy, a broadened approach to sustainability led to social participation and gender being incorporated as key priorities, while global responsibility has been a historic focus.

At the same time, Bonn's Sustainability Strategy also reflects state-level priorities such as climate protection and the transition towards sustainable urban development, including environmentally friendly energy and transport. These priorities correspond to particular challenges in a state identified as the "industrial heartland" of Germany and which accounts for one-third of the country's greenhouse gas emissions. Adopted in June 2016, the NRW Sustainability Strategy includes 19 priority fields of action and 7 cross-departmental focus areas. These focus areas are: i) the climate protection plan; ii) the green economy strategy; iii.) the biodiversity strategy; iv.) sustainable financial policy; v.) sustainable development of urban areas and neighbourhoods; vi) demographic change and suitable neighbourhoods for the elderly; and vii) the NRW initiative "Together in NRW for a life without poverty and marginalisation" (State of North Rhine-Westphalia, 2016[2]). NRW's strategy was among the first state-level strategies in Germany to include the 2030 Agenda and the SDGs. Although the strategy takes a holistic approach to sustainability, the SDGs have been added by mapping existing key indicators to the SDGs, rather than using the goals as a strategic focus. Special attention is also paid to Education for Sustainable Development (ESD) to integrate it throughout the education system in NRW. Accordingly, ESD is an important topic of Bonn's Sustainability Strategy.

\section{Co-ordination mechanisms in place}

At the federal government level, the German sustainable development strategy is co-ordinated at the highest level under the responsibility of the State Secretaries' Committee (SSC) chaired by the Federal Chancellery, ensuring political leadership and facilitating cross-sectoral collaboration. Länder and local authorities are invited to SSC meetings when relevant and were consulted in the preparation of the national strategy through their representative bodies and umbrella associations. Two sections in Chapter $D$ of the strategy - "Sustainable Development: All are Partners" - include contributions by the Länder and the German Association of Municipal Umbrella Organisations and point to the role of subnational governments in the implementation of the 2030 Agenda and the SDGs (The Federal Government, 2016[1]). 
Beyond strategy formulation, Germany's Council for Sustainable Development supports vertical co-ordination across levels of government regarding the 2030 Agenda. For example, the council has created four regional hubs (RENN) to improve the vertical co-ordination of the implementation of the federal strategy and the SDGs. This follows recommendations made in the second peer review of the German Sustainable Development Strategy by international experts in 2013, which found that horizontal and vertical co-ordination needed to be strengthened (Stigson et al, 2013, cited in von Hauff and Kuhnke $\left.\left(2017_{[3]}\right)\right)$. The network organisation LAG 21 NRW - which supported the development of Bonn's Sustainability Strategy and runs the Bonn based office of RENN west - is the lead partner of the RENN in western Germany, reinforcing Bonn's position as a sustainability hub.

The federal government actively supports cities and municipalities in implementing the 2030 Agenda, both within Germany and through global partnerships. One example is the pilot project Municipalities for Global Sustainability, in which Bonn was 1 of 15 pilots in NRW (see Chapter 1). Through this project funded by the federal government, LAG 21 NRW worked directly with the cities and municipalities to support them in the development of local sustainability strategies. The NRW government participated with two representatives in the advisory council of the project, alongside the state chancellery. Another example of federal government engagement with local governments is the inter-ministerial working group for sustainable urban development (IMA Stadt), where the Association of German Cities and the German Association of Towns and Municipalities represent the interests of German cities and municipalities (Federal Ministry of the Environment, Nature Conservation and Nuclear Safety, 2017[4]). Finally, the German Sustainable Development Council engages with municipalities through the Lord Mayors network and its "Sustainable City" dialogue, in which the mayor of Bonn participates.

Despite the institutional frameworks in place for both horizontal and vertical co-ordination, measuring progress towards the SDGs remains a challenge in the context of Germany's federal system, where local authorities enjoy high levels of autonomy. While the national sustainable development strategy emphasises the importance of "achieving the highest possible compatibility of the indicator systems of the federal government and the Länder regarding sustainable development" (The Federal Government, $\left.2016_{[1]}\right)$ different indicator sets are developed in parallel across municipalities and states, with limited vertical co-ordination, reflecting the different government competencies. The national statistics office works mostly with the Länder, which in turn rely on their engagement with municipalities. In some cases, municipalities are invited to participate in the meetings of the inter-ministerial working group on the SDGs at the national level. A step in the right direction is the catalogue of SDGs localised indicators developed by the Bertelsmann Foundation, which contributes to harmonisation efforts and comparability across German cities. Building on that framework among others, the city of Bonn prioritised in its sustainability reporting 55 indicators that were most relevant to local conditions and competencies. 17 of the 47 indicators developed by the Bertelsmann Foundation are traditionally used in Bonn's sustainability reports; in the current report an additional 11 indicators from the Bertelsmann Foundation's set have been included (Box 1.2).

The engagement of German cities in Voluntary National Reviews (VNRs) is still rather limited. Similarly, the German Association of Cities, which has created an online application to report on municipal performance on the SDGs, is not engaged in the VNRs by the federal government. Engaging German cities further and more systematically in the VNR process could be a significant incentive towards disaggregated, harmonised and comparable SDGs data to unpack regional disparities in the various dimensions of the 2030 Agenda and support place-based action. It would also allow to share good practices on the implementation of the SDGs at the local level and set a mechanism to converge, accelerate and upscale the Voluntary Local Reviews. Bonn will publish its first VLR in July 2020, being one of the very few cities in Germany to prepare such a report. 


\section{Collaboration between German cities and municipalities on the 2030 Agenda}

The German Association of Cities advocates for the interests of German cities and promotes the idea of "local self-government" to the federal and Länder governments, the European Union, as well as nongovernmental organisations. The association initiated the resolution by municipalities on the $2030 \mathrm{Agenda}$, so far signed by more than 140 German municipalities, including Bonn, which was among the first ones to sign. The association has also worked in a joint initiative with the Bertelsmann Foundation to develop indicators for municipalities on the SDGs and is supporting cities in a wide range of policy areas, including energy, climate change and water. Another project led by the association focuses on developing a methodology for attributing local contributions towards Nationally Determined Contributions (NDCs) in the framework of the United Nations Framework Convention on Climate Change (UNFCCC), raising the profile of local governments as "implementers" of sustainable development strategies.

Strategic collaboration is taking place between Bonn and neighbouring municipalities around themes such as mobility, business development, education and culture, albeit so far without direct reference to the SDGs. It is expected that the pilots participating in the Municipalities for Global Sustainability project will continue to exchange information on the implementation progress of their sustainability strategies. This further exchange will also be supported by the federal government.

\section{The SDGs as a tool to engage the private sector and civil society in Bonn's Sustainability Strategy}

\section{Bonn as a growing hub for sustainability-oriented businesses}

A growing number of small and medium-sized enterprises (SMEs) focusing on sustainability as part of their core business has developed in Bonn around the international organisations located in the city. The proximity offered by Bonn as a medium-sized city, as well as its access to a rich network of sustainability actors from the science and research domains, contribute to the evolution of Bonn as an attractive environment for social entrepreneurship and business networks. In addition, in 2016, the Chamber of Industry and Commerce Bonn/Rhein-Sieg set up a dedicated corporate social responsibility (CSR) centre in Bonn, initially funded for a three year period and subsequently expanded to the regional level, acting as a platform of CSR ambassadors who nurture the CSR culture locally. Among others things, the ambassadors can facilitate contacts with the "Senior Expert Service", a foundation of the German industry for international cooperation. One example of a newly established business network in Bonn is related to the "superfood" plant Moringa and the sustainability of its supply chain. Other themes that currently stimulate businesses to work together are around investment in Ghana and digitalisation in Africa. These examples show that there are fertile grounds to engage the private sector in the SDGs.

Large corporations located in Bonn, including Deutsche Telekom and DHL, also demonstrate their commitment towards sustainability, both through CSR and in their operations on a global level. For DHL specifically, this translates into a commitment of zero $\mathrm{CO}_{2}$ emissions by 2050 by creating an entirely electric fleet of delivery vehicles for example. The local imprint of DHL through the headquarters - the Post Tower - plays a part in the company's "CSR narrative", where dynamic light installations mark important occasions, such as the COP23 and the Beethoven festival (Deutsche Post DHL Group, 2019 ${ }_{[5]}$ ). DHL is also part of the United Nations (UN) Global Compact to demonstrate its commitment to the 2030 Agenda. Deutsche Telekom asks their suppliers to meet higher social and environmental standards than required by law and provides a development programme for key suppliers covering environmental protection, working hour regulations and occupational health and safety (Deutsche Telekom AG, 2020[6]).

In Germany, key barriers for sustainable products have traditionally been consumer attitudes and a "discount-driven market", especially in the food industry with discount stores such as Lidl, Netto and Penny 
where the majority of Germans buy at least part of their weekly groceries (Schmeller, $2014_{[7]}$ ). While the introduction of Fair Trade goods also in discount stores might influence consumer behaviours, as of 2019 only EUR 18 per person were spent on Fair Trade products on a yearly basis in Germany (Forum Fairer Handel, $\left.2019_{[8]}\right)$. To address this issue, education could be one key channel to shape awareness and consumption habits. For many years, Bonn has been inviting all citizens to participate in fair trade and consumption during the Fair Week every September, with a comprehensive 14-day programme.

\section{Private sector engagement: A future focus in Bonn's Sustainability Strategy}

Although the private sector was invited to the project working group for the development of the 2019 Sustainability Strategy, low representation by the business community has been identified as a key weakness. In Bonn, the perception that the key driving forces of sustainable development are UN organisations, non-governmental organisations (NGOs), academia and the public sector led to overlooking the essential role of the private sector in the strategy development. Among private businesses, the city administration estimated that small and medium-sized companies (SMEs) are more closely involved in local development than big corporations. To further stimulate SMEs and to further involve the business sector, the department for economic promotion of the city of Bonn has worked together with partners like the Social Impact Lab Bonn, the Efficiency Agency NRW, the Chamber of Industry and Commerce and neighboring cities and districts organising workshops and networking events as well as offering information services. Creating an official platform connecting private actors around sustainability could offer new opportunities to leverage the potential contributions of the business community for the SDGs.

\section{Bonn's actions to raise civil society awareness on the SDGs}

Bonn has made great efforts to raise awareness on the SDGs among the public, through creative and varied communications and engagement campaign, including through the Bonn SDG Days, annually organised in relation to the German Sustainability Days and the European sustainability week in May and June (Box 3.1). Another successful initiative in Bonn are the Climate Ambassadors, whereby students in primary schools receive a climate "driving licence". In 2019, a total of 2080 third-grade students from 34 primary schools received the licence. During the SDG Days 2018, the climate licences were handed over by the mayor to one participating primary school class, representing all participating pupils. Since the project started in 2012, more than 12000 students from around one-third of the city's primary schools have become climate ambassadors. In addition, the Climate Ambassador concept has been transferred to local schools in La Paz (Bolivia), Chengdu (China), Cape Coast (Ghana) and Bukhara (Uzbekistan). This shows how the 2030 Agenda helps to unite efforts at home and abroad, rather than treating global responsibility as a separate activity. This approach is in line with the ambition of the 2030 Agenda to make the goals universally applicable for both developed and developing nations.

\section{Box 3.1. Bonn SDG Days}

The concept of the first Bonn SDG Days in 2018 was formed around the motto "17 Days for 17 Goals", with at least 1 event on the SDGs taking place every day for 17 days from 27 May to 13 June 2018 . The overall aim was to make the SDGs and the work undertaken in Bonn more visible and advocate for wide support for the SDGs by showcasing individual actions that can be taken to contribute. A second edition was held in 2019, when the SDG Days took place during a period of 2 months in May and June, following the motto "17 Events for the 17 Goals". The third SDG Days with the motto: "Together for the 17 Goals" were planned from 18 May to 7 June 2020, but had to be cancelled due to the corona pandemic. 
Activities included bike tours to sustainable projects in Bonn, an evening walk to urban gardening projects on municipal land, SDG poetry slams and pub quizzes as well as special events on topics such as biodiversity conservation or migration. As Bolivia and Ghana are key partners in the city's international co-operation activities, a Ghanaian dance theatre performed and several workshops in 2018, while an artist from Bolivia was invited to join the special event "One World Construction Site" in 2019. In co-operation with an artist from Bonn, the Bolivian artist designed an SDG mural to further anchor the SDGs in the city's landscape and in the minds and actions of Bonn's citizens. Information stands were also set up at large city events such as the annual Museum Mile Festival where visitors were invited to spin the popular SDG "wheel of fortune" and received key information about the different SDGs and concrete implementation measures in Bonn.

The Bonn SDG Days activities also allowed for a lively exchange between citizens, informing them about initiatives such as urban gardening and attracting large media coverage. The opening of the Bonn SDG Days 2019 was directly linked to the "Global Festival of Action", organised by the Bonn-based UN Action Campaign. About 1500 people from all over the world exchanged best practice examples and impulses for action to implement the SDGs at the World Conference Center Bonn (WCCB) from 2 to 4 May 2019. They carried the SDGs in a colourful march from the WCCB to the big festival "Rhine in Flames" which took place at the same time in Bonn.

Source: City of Bonn (2020[9]], Die SDGs in Bonn [The SDGs in Bonn], https://www.bonn.de/themen-entdecken/uno-internationales/sdgsbonn.php; City of Bonn (2018[10]]), Bonner SDG-Tage. 17 Tage für die 17 Ziele [Bonn's SDG Days. 17 Days for the 17 Goals], https://www.local2030.org/events/243/Flyer.pdf.compressed.pdf.

In addition to the SDG Days, another awareness-raising initiative is the annual fair breakfast including a fair fashion show of local stores in the city centre. A video of this event was showcased in New York during the celebration of the third anniversary of the SDGs in 2018. The UN Day in Bonn presents another opportunity to engage the public in the city's work on the SDGs. Finally, the city has developed postcards for distribution and with suggestions on how individual action can contribute to the SDGs and another set showing what the city is doing to address them. For example, one postcard informs the locals about the fact that all the employees in the Office for Green Spaces and Parks wear "fair" uniforms procured by the city administration using fair procurement principles, contributing to SDG 12. For online audiences, the city has launched a hashtag that allows citizens to follow its actions (\#BonnAct4SDGs).

Citizens can also be an engine behind the implementation of the SDGs through social participation in urban development, linking social and environmental goals. For instance, in 2012, Tannenbusch, a relatively disadvantaged neighbourhood in Bonn, started participating in the initiative "Social City Tannenbusch" to address the uneasy co-existence of the local population in a neighbourhood characterised by high-rise buildings (Box 3.2).

\section{Box 3.2. Social City Tannenbusch}

\section{Fostering social participation through district management}

A central feature of Social City Tannenbusch is its district management, including four district managers responsible for different areas of the neighbourhood. Their key role is to provide a connection point between the local administration, residents and other actors, and to answer questions, complaints and requests for help and suggestions. To this end, they run a district management office open twice per week. 
The district management team also manages a project fund for small-scale neighbourhood-related projects (up to EUR 3000 per project). The district managers advise on applications, whereas a jury of residents decides on the final funding. Since the start in October 2012, 63 projects have been funded to a total amount of approximately EUR 170 000. Making residents jury members has generated a very constructive working environment, where residents assigned as "decision-makers" and "experts" make them multipliers for positive change in their home areas.

Other activities by the district management include the Tannenbusch Forum, where neighbourhoodrelated topics like integration, public spaces, garbage collection and cleanliness are discussed. In the 2014 version of the forum, a discussion around garbage collection and cleanliness led to the formation of a working group to address the situation. Co-ordinated by the district management team, the group involved residents, landlords, representatives of the city administration, schools, local initiatives and other local actors.

Social City Tannenbusch was initially funded within the framework of the programme of the Federal government and the federal states (Bund-Länder-Programm "Soziale Stadt") for 2012-17. Since 2018, the district management continues receiving support from the office of Social Affairs and Housing of the City of Bonn. There is also an advisory board, which is composed by the representatives of the political parties of the city council and which supports and advises on the process of neighbourhood development. The Social City Tannenbusch provides a good example of how social participation in urban planning can be addressed at the neighbourhood scale. This is a crucial aspect of SDG 11, which is a cross-cutting priority identified for the city of Bonn in the implementation of the SDGs.

Source: City of Bonn (n.d.[11]), Der Stadtteil Bonn Neu-Tannenbusch [The District Bonn Neu-Tannenbusch], https://www.neutannenbusch.de/willkommen/soziale-stadt/.

\section{References}

City of Bonn (2020), Die SDGs in Bonn [The SDGs in Bonn], https://www.bonn.de/themenentdecken/uno-internationales/sdgs-bonn.php.

City of Bonn (2018), Bonner SDG-Tage. 17 Tage für die 17 Ziele [Bonn's SDG Days. 17 Days for the 17 Goals], https://www.local2030.org/events/243/Flyer.pdf.compressed.pdf.

City of Bonn (n.d.), Der Stadtteil Bonn Neu-Tannenbusch [The district Bonn Neu-Tannenbusch], https://www.neu-tannenbusch.de/willkommen/soziale-stadt/.

Deutsche Post DHL Group (2019), Post Tower - Headquarters of Deutsche Post DHL Group, Brochure, https://www.dpdhl.com/content/dam/dpdhl/en/media-center/mediarelations/documents/dpdhl-group-post-tower-brochure-03-2019.pdf.

Deutsche Telekom AG (2020), Supply Chain Management, https://www.telekom.com/en/corporate-responsibility/assume-responsibility/assumeresponsibility/supply-chain-management-355304 (accessed on 22 May 2020). 
Federal Ministry of the Environment, Nature Conservation and Nuclear Safety (2017), Bericht des interministeriellen Arbeitskreises "Nachhaltige Stadtentwicklung in nationaler und internationaler Perspektive" (IMA Stadt) 2017 [Report of the Interministerial Working Group "Sustainable Urban Development" (IMA Stadt) 2017], https://www.bmu.de/fileadmin/Daten BMU/Download PDF/Nachhaltige Entwicklung/ima sta dt bericht bf.pdf (accessed on 31 May 2020).

Forum Fairer Handel (2019), Zahlen und Fakten zum Fairen Handel in Deutschland [Facts and Figures on Fair Trade in Germany], http://www.forum-fairer-handel.de/fairer-handel/zahlenfakten/.

Schmeller, J. (2014), "Germany a key market for fair trade products", DW Business, https://p.dw.com/p/1Bukp (accessed on 22 May 2020).

State of North Rhine-Westphalia (2016), Sustainability Strategy for North-Rhine Westphalia, https://www.nachhaltigkeit.nrw.de/fileadmin/download/sustainability strategy for north rhinewestphalia.pdf.

The Federal Government (2016), German Sustainable Development Strategy, https://www.bundesregierung.de/breg-en/issues/sustainability/germany-s-nationalsustainable-development-strategy-354566.

von Hauff, M. and C. Kuhnke (eds.) (2017), Sustainable Development Policy, Routledge, https://doi.org/10.4324/9781315269177.

\section{Notes}

${ }^{1}$ Including cities, towns and municipalities, and administrative districts.

${ }^{2}$ A further update was made to the German Sustainable Development Strategy in 2018, in particular in regards to climate targets. However, the later update did not significantly change the structure of the strategy adopted in the 2016 revision. For more information see: https://www.bundesregierung.de/bregen/issues/sustainability/germany-s-national-sustainable-development-strategy-354566. 


\section{Policy recommendations for $A$ Territorial Approach to the SDGs in Bonn, Germany}

This final section suggests policy recommendations to enhance the territorial approach to the SDGs in the city of Bonn, Germany, and tackle urban challenges that hinder sustainable development. The recommendations span from the need to institutionalise and allocate adequate resources to the 2019 Bonn Sustainability Strategy, to the importance of managing trade-offs between the need to achieve climate objectives, improve sustainable mobility, ensure affordable housing and reduce inequalities. Strengthening the engagement of the business community in the Sustainability Strategy and the involvement of German cities in the voluntary national reporting on the SDGs are also key recommended actions. 


\section{Policy recommendations}

\section{Box 4.1. OECD Checklist for Public Action to localise the SDGs in cities and regions}

The OECD Checklist for Public Action, released in 2020, is directed at governments at all levels to facilitate the implementation of a territorial approach to the SDGs. The checklist provides action-oriented recommendations around five main categories:

- Planning, policies and strategies: Use the SDGs to define and shape local and regional development visions, strategies, plans, and re-orient existing ones. Cities and regions should use the SDGs to address local challenges that require a holistic approach, such as clean forms of urban mobility, affordable housing, gender equality, access to green spaces, balanced urban development, clean water and sanitation, air quality, solid waste management, territorial inequalities, or service delivery.

- Multi-level governance: Use the SDGs as a framework to align policy priorities, incentives, objectives across all levels of governments as well as to manage trade-offs and promote synergies across policy areas. In particular, regions and cities should be engaged in the process of Voluntary National Reviews to reflect progress at the subnational level and address regional disparities. Voluntary Local Reviews can also drive better multi-level governance of the SDGs and shed light on local initiatives.

- Financing and budgeting: Mainstream the SDGs in budgeting processes to ensure adequate resources are allocated for the implementation of the 2030 Agenda and to foster policy continuity across political cycles. Governments should allocate financial resources based on the identified place-based policy priorities and local challenges, and use the SDGs framework to foster multi-sectoral programmes and priorities.

- Data and information: Leverage SDGs data and localised indicator systems to guide policies and actions to better people's lives, and to showcase the performance and positive stories of cities and regions. In particular, for more comprehensive assessment and policy responses, cities and regions should combine data and indicators at different scales, including administrative boundaries (unit for political and administrative action) and functional approaches (economic geography of where people live and work).

- Engagement: Use the SDGs as a vehicle to enhance accountability and transparency through engaging all territorial stakeholders, including civil society, citizens, youth, academia and private companies, in the policymaking process. Cities and regions should use a combination of various tools to engage local stakeholders, such as awareness-raising campaigns, networking opportunities, but also de-risking investments in SDG solutions through grants or loans, as well as a fiscal incentive for innovative solutions towards sustainability.

Source: OECD (2020[1]), A Territorial Approach to the Sustainable Development Goals: Synthesis Report, https://doi.org/10.1787/e86fa715-en.

The city of Bonn has a long history of sustainable development, which provides fruitful grounds for implementing its newly developed Sustainability Strategy and overcoming some of the challenges faced by the city. Moving forward, some key actions can be considered to make the most of this potential:

\section{Planning, policies and strategies}

- Raise the profile of the Sustainability Strategy to co-ordinate the implementation of the SDGs and the city's climate agenda in a holistic manner. To ensure this, Bonn should strive to 
consolidate and institutionalise the different platforms, groups and structures that were set up to shape the 2019 Sustainability Strategy. With the city council decision on the Sustainability Strategy, the continuation of the cross-departmental steering group was already confirmed. The mayor also set up an advisory expert group to consult on the implementation, which met for the first time in March 2020. In addition, the multi-stakeholder working group provides useful co-ordination mechanisms for the implementation of the strategy. This institutionalisation (e.g. in the city administration structure) will help foster policy continuity to ensure continued efforts in the long run to implement and further develop the strategy through 2030.

- Use the SDGs to strengthen the link between the climate agenda and the social and economic dimensions of sustainability. Considering the relatively stronger focus on environmental aspects of sustainability in Bonn and Germany overall, the SDGs could provide a useful tool to link more explicitly the environment with other more social and economic goals. In particular, the city of Bonn should:

- Consider the impact of climate measures on inequality, with special attention to vulnerable groups, in particular to the elderly population and youth.

- Manage the trade-offs between providing additional affordable housing - due to rising rents and old-age poverty - and maintaining and developing green spaces (SDG 11 or 15) to achieve climate objectives. Compensatory measures for vulnerable groups should also be considered.

- Consider the transport needs of a growing and elderly population when designing measures to reduce private transportation in favour of public transport to reduce air pollution.

- Stimulate the provision of clean and affordable energy as well as energy efficiency to generate cost savings and have positive effects for low-income populations.

- Support the implementation of sustainability related initiatives in the business sector and encourage the inclusion of climate objectives within the start-up community to stimulate the economic structural change of the city by fostering innovation, creating sustainable jobs and enhancing entrepreneurship.

- Link more explicitly the sustainability reporting to policy design and implementation in Bonn so that it can really drive the policy agenda of the city. The rich evidence base provided by the Sustainability Report, coupled with the international comparisons stemming from the OECD localised indicator framework, should help effectively guide priority setting, policymaking and budget allocation over the years to come. In its next versions, the Sustainability Report should be more strongly connected to the sustainability targets set within the Sustainability Strategy and thus be a good baseline leading to concrete policy guidelines/recommendations addressed to the mayor and/or city council to trigger action and change. Accordingly, the VLR (2020) of the city of Bonn is being clustered around the thematic priorities of the Sustainability Strategy.

\section{Multi-level governance}

- Strengthen the vertical co-ordination for implementing, measuring and monitoring the SDGs, with direct engagement of German cities and municipalities in national processes. The Service Agency Communities in One World on behalf of Engagement Global and the German Associations of Cities and Municipalities can play a key role in advocating for enhanced engagement of cities at the federal level. The 2021 Voluntary National Review (VNR) provides an opportunity for increased visibility of the SDGs-related commitment from the city of Bonn and peer cities in the country. To raise its profile nationally and internationally (including at the UN HighLevel Political Forum), the city can start to align its reporting on SDGs progress more closely with the UN format for the VNR so that the national reporting for Germany can feature disaggregate data that can unpack regional disparities in the country. The city of Bonn has undertaken a first step in this direction with its first VLR to be launched in July 2020. 
- Use the SDGs framework to facilitate both horizontal and vertical co-ordination and to convene stakeholders across sectors to address interlinked challenges. In this regard, as in the development of the strategy, departments working on economic and social issues in the city of Bonn, including the business development department, need to engage with those working on environmental issues and international co-operation in order to identify synergies and potential trade-off in the course of implementing the Sustainability Strategy in Bonn.

- Leverage the potential of Bonn's metropolitan area to promote sustainable urban development at the right scale. The SDGs could provide a common language to foster innovative governance arrangements for greater co-operation with other municipalities, in particular on policies that are better managed at the metropolitan scale such as transport, land use or housing.

\section{Financing and budgeting}

- Pursue ongoing efforts to mainstream the SDGs in budgeting processes to ensure adequate resources are allocated to the implementation of Bonn's Sustainability Strategy and the 2030 Agenda, and to ensure policy continuity across political cycles. In the implementation phase of the 2019 Sustainability Strategy, financial resources should be allocated based on local policy priorities, challenges and expected impact therein identified. The impact-oriented budgeting for selected sustainability targets implemented in four pilot areas within the city's budgeting process for 2020/2021 is a first step in this direction and should be scaled up. The SDGs can also be used as a means to foster integrated multi-sectoral programmes and priorities, in particular between initiatives and projects in the Sustainability Strategy and the Climate Emergency package.

- Use the SDGs and Bonn's Sustainability Strategy to mainstream sustainability criteria in public procurement processes. Tools such as sustainable public procurement can help leverage funds from the private sector to achieve economic, social and environmental outcomes aligned with the SDGs. Clear criteria to promote sustainability should be formulated and applied in Sustainable Public Procurement.

\section{Data and information}

- Leverage Bonn's sustainability indicators and the OECD localised SDGs indicator framework to build an actionable evidence-based system that can guide policy choices and decisions. In particular, for more comprehensive assessment and policy responses to sustainable development challenges, Bonn could:

- Use data from the sustainability report to identify key local development challenges and define policy priorities.

- Combine data and indicators at different scales, from those related to administrative boundaries (developed by the city of Bonn) to those related to functional urban areas (OECD localised SDGs indicator framework), to better address local development challenges at the right scale (transport, housing, inclusion).

- Use national and international benchmarking to identify areas for improvement, connect to peers that face similar sustainability challenges and foster best practice exchanges.

- Use the data and qualitative information (e.g. storytelling, community of practices) to showcase the performance and positive stories of Bonn on the SDGs. The latter can help engage with citizens, increase the transparency of the actions towards the SDGs, and showcase the SDGs as a collective effort towards implementation. 


\section{Engagement}

- Step up Bonn's efforts to connect with the business community and leverage the potential of the private sector to contribute to the SDGs. The Chamber of Industry and Commerce already identified Bonn as a vibrant location for social entrepreneurship. A platform that allows businesses to connect with each other - as indicated in the Sustainability Strategy - can be a key to strengthen the contribution of the private sector towards the SDGs. There is explicit demand from business representatives in Bonn for having such a platform.

- Strengthen the SDGs component in awareness-raising activities beyond the climate and environmental sustainability, including in the adult education and training system. This could stimulate enhanced awareness of sustainable production and consumption habits among citizens in general, and future consumers, entrepreneurs and employees in particular. The Climate Ambassador initiative provides a successful model that can be further expanded in this regard. Mobility is another area where awareness-raising efforts can be further used to promote public transport or cycling instead of individual motorised transport, explaining its negative impact on climate change and other SDGs, as the city started doing with the "Jobwärts" initiative. Finally, awareness-raising and education activities can be shaped around the UN High-Level Political Forum agenda to connect local actions with global visibility.

- Consider peer-learning between Bonn, other German cities as well as other cities outside Germany engaged in the localisation of the SDGs. This can help to improve certain aspects of the implementation of the 2019 Sustainability Strategy such as budgeting (e.g. Mannheim could be a good peer) or private sector involvement (e.g. Kitakyushu). Bonn should also consider exchanging knowledge with the cities that have also been developing VLRs to assess costs and benefits of engaging in this process and shape a greater contribution to vertical co-ordination of SDG reporting in Germany. The German Association of Cities and Engagement Global are two key players to facilitate this process.

\section{References}

OECD (2020), A Territorial Approach to the Sustainable Development Goals: Synthesis Report, OECD Urban Policy Reviews, OECD Publishing, Paris, https://doi.org/10.1787/e86fa715-en. 
More information: oe.col/sdgs-local

Follow us on Twitter: @OECD_local

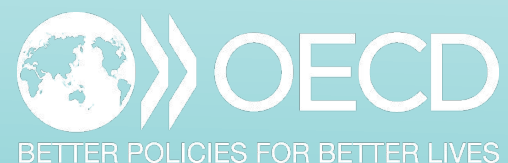

